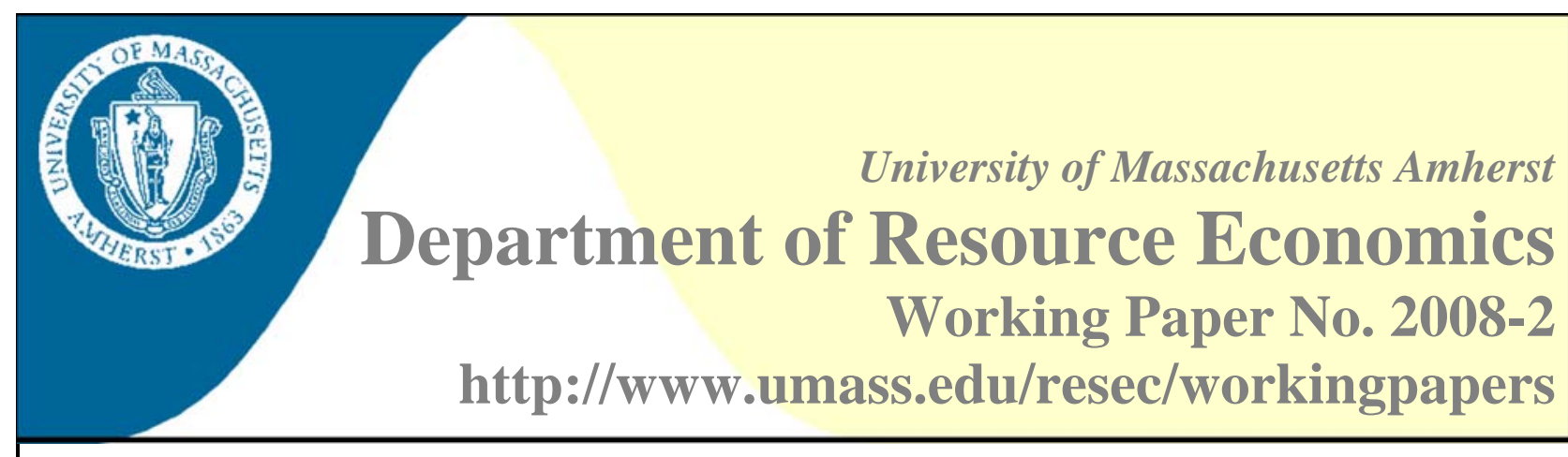

\title{
The Problem of Maintaining Compliance within Stable Coalitions: Experimental Evidence
}

\author{
David M. McEvoy ${ }^{1}$, James J. Murphy ${ }^{2}$, John M. Spraggon ${ }^{3,}$, and John K. Stranlund ${ }^{4}$
}

\begin{abstract}
:
This study examines the performance of stable cooperative coalitions that form to provide a public good when coalition members have the opportunity to not comply with their commitments. A stable coalition is one in which no member wishes to leave and no non-member wishes to join. To counteract the incentive to violate their commitments, coalition members fund a third-party enforcer. This leads to the theoretical conclusion that stable coalitions are larger (and provide more of a public good) when their members must finance enforcement relative to when compliance is ensured without the need for costly enforcement. However, our experiments reveal that giving coalition members the opportunity to violate their commitments while requiring them to finance enforcement to maintain compliance reduces the overall provision of the public good. The decrease in the provision of the public good is attributed to an increase in the participation threshold for a theoretically stable coalition to form and to significant levels of noncompliance. When we abandon the strict stability conditions and require all subjects to join a coalition for it to form, the average provision of the public good increases significantly.
\end{abstract}

Keywords: stable coalitions, self-enforcing agreements, compliance, enforcement, public goods

JEL Classification: H41, C92

${ }^{1}$ David M. McEvoy, Economics Department

Appalachian State University, Raley Hall

416 Howard Street, ASU Box 32051, Boone, NC 28608

E: mcevoydm@appstate.edu P: 828-262-6126 F: 413-545-5853

${ }^{2}$ James Murphy, Department of Economics

University of Alaska Anchorage, 201-D Rasmuson Hall

3211 Providence Drive, Anchorage, AK 99508

E: murphy@uaa.alaska.edu P: 907-786-1936 F: 907-786-4115

${ }^{3}$ John M. Spraggon, Department of Resource Economics

University of Massachusetts, 212A Stockbridge Hall

80 Campus Center Way, Amherst, MA 01003-9246

E: jmspragg@resecon.umass.edu P: 413-545-6651 F: 413-545-5853

${ }^{4}$ John K. Stranlund, Department of Resource Economics

University of Massachusetts, 214 Stockbridge Hall

80 Campus Center Way, Amherst, MA 01003-9246

E: stranlund@resecon.umass.edu P: 413-545-6328 F: 413-545-5853 
May 2008

\title{
The Problem of Maintaining Compliance within Stable Coalitions: Experimental Evidence
}

\author{
David M. McEvoy* \\ Department of Economics \\ Appalachian State University \\ James J. Murphy \\ Department of Economics \\ University of Alaska Anchorage \\ John M. Spraggon \\ Department of Resource Economics \\ University of Massachusetts, Amherst \\ John K. Stranlund \\ Department of Resource Economics \\ University of Massachusetts, Amherst
}

Acknowledgements: Funding for this project was provided from the Center for Public Policy and Administration, University of Massachusetts, Amherst. The authors would like to thank Emily Caffery and Glenn Caffery for their help with designing and programming the experimental software for this research. The authors also gratefully acknowledge the helpful comments of Erin Baker and David Dickinson.

\footnotetext{
* Correspondence to: David M. McEvoy, Economics Department, Appalachian State University, Raley Hall, 416 Howard Street, ASU Box 32051, Boone NC 28608. Phone: 828-262-6126. Email: mcevoydm@appstate.edu.
} 


\title{
The Problem of Maintaining Compliance within Stable Coalitions: Experimental Evidence
}

\begin{abstract}
This study examines the performance of stable cooperative coalitions that form to provide a public good when coalition members have the opportunity to not comply with their commitments. A stable coalition is one in which no member wishes to leave and no non-member wishes to join. To counteract the incentive to violate their commitments, coalition members fund a third-party enforcer. This leads to the theoretical conclusion that stable coalitions are larger (and provide more of a public good) when their members must finance enforcement relative to when compliance is ensured without the need for costly enforcement. However, our experiments reveal that giving coalition members the opportunity to violate their commitments while requiring them to finance enforcement to maintain compliance reduces the overall provision of the public good. The decrease in the provision of the public good is attributed to an increase in the participation threshold for a theoretically stable coalition to form and to significant levels of noncompliance. When we abandon the strict stability conditions and require all subjects to join a coalition for it to form, the average provision of the public good increases significantly.
\end{abstract}

\section{JEL Codes: H41, C92}

Keywords: stable coalitions, self-enforcing agreements, compliance, enforcement, public goods

\section{Introduction}

The analysis of stable coalitions is important in many contexts, including the formation of cartels (D’Aspremont et al. 1983; Diamantoudi 2005), voluntary environmental agreements (Carraro and Siniscalco 1993; Barrett 1994; Kolstad 2007; Dawson and Segerson 2008), the provision of threshold public goods (Van de Kragt 1983; Dawes et al. 1986; Marks and Croson 1998) and industry mergers (Vasconcelos 2006). Although many definitions of coalitional stability exist, the concept initially proposed by D’Aspremont et al. (1983) is frequently adopted. According to D’Aspremont et al. (1983), a coalition is considered stable if no existing member wishes to leave (internal stability) and no non-member wishes to join (external stability). With identical agents, these two conditions ensure that a stable coalition is unique, consisting of the minimum number of members such that each are better off than in the absence of any cooperation. In other words, a stable coalition is the minimum sized profitable coalition. Most economic analyses of these types 
of coalitions are concerned primarily with individual agents' incentives to participate in, or defect from, a group of cooperating members. As a result, the term 'stable' is somewhat narrow as it refers exclusively to defining the number of members in a coalition, not with their decisions to cooperate after joining.

Without enforcement, however, individuals may first join a coalition to make certain that it satisfies a minimum membership requirement for formation, and then later renege on their commitments in an attempt to free ride off those members that continue to cooperate. For example, nations may become party to an international environmental agreement with the sole intention of satisfying a minimum membership requirement so that an agreement can enter into force. Later, if compliance is not adequately enforced, nations may find it in their interest to violate the terms of the agreement. In general, inadequate enforcement within coalitions can undermine the objectives of cooperative agreements and even prevent them from forming at all.

Despite the fact that the commitments of coalition members need to be enforced, little attention has been paid to this problem. In fact, most authors who examine stable coalitions simply assume that their members will comply fully with the terms of a cooperative agreement (e.g. D’Aspremont et al. 1983; Carraro and Siniscalco 1993; Barrett 1994; Kolstad 2007; Dawson and Segerson 2008). In contrast, this study evaluates the performance of stable coalitions in which all members have the opportunity to violate their commitments and, consequently, fund a third-party enforcer to maintain compliance. Our study consists of a theoretical analysis of the impact of member-financed enforcement on the size of stable coalitions and their provision of a public good, as well as laboratory experiments to test the main hypotheses of the theoretical model. 
Our theoretical model suggests that member-financed enforcement of compliance within coalitions can lead to greater participation and greater provision of a public good than when compliance is assured without cost. This is intuitive because more cooperation is necessary to offset the additional costs of enforcement to make a coalition profitable. To test this theoretical result we conducted a series of experiments that utilize a threshold public good framework similar to those of Van de Kragt et al. (1983), Bagnoli and McKee (1991), and Marks and Croson (1999), but with the added compliance and enforcement dimensions. However, our experimental results flatly reject the hypothesis that member-financed enforcement within stable coalitions leads to greater provision of a public good. Relative to the theoretical predictions, as well as to baseline experiments that did not allow subjects the opportunity to be noncompliant, requiring member-financed enforcement actually decreased the average provision of the public good.

Our experimental design allows us to explain the poor performance of stable coalitions with member-financed enforcement in terms of the two factors that change when giving coalition members the opportunity to violate their commitments while requiring them to finance an enforcer to maintain compliance. The first is the compliance decision itself and the second is the theoretical outcome that the individual cost of financing enforcement leads to a higher participation threshold if coalitions with member-financed enforcement are to form. We demonstrate that both factors contributed to the poor showing of stable coalitions with memberfinanced enforcement. Like other authors (Van de Kragt et al. 1983; Dawes et al. 1986; Suleimen and Rapoport 1992; Rapoport and Suleimen 1993; Cadsby and Maynes 1999) we find that increasing the participation threshold lowered the average provision of a public good because coalitions formed less frequently. Moreover, even though we structured the compliance 
incentives so that each member of a coalition had the financial motivation to comply, a significant number did not.

Because theoretically stable coalitions with member-financed enforcement performed so poorly, we conducted another set of experiments with which we abandoned the restrictive internal and external stability requirements of stable coalitions and examined the performance of a coalition that was costly to enforce, but required full participation to form. This requirement did not change average compliance rates within coalitions, but it significantly increased both the frequency of coalition formation and the overall provision of the public good. Our results suggest important lessons for the determination of threshold rules for coalition formation and for enforcing compliance within coalitions. Improving coalition formation and compliance within coalitions requires a higher participation threshold, perhaps full participation, and more stringent enforcement than suggested by theory.

\section{Stable coalitions to provide a public good}

In this section we present simple models of the formation of coalitions to provide a public good that form the basis for our experiments. In particular we derive equilibrium levels of participation in these coalitions when they require member-financed enforcement and when they do not. Comparing these participation levels provides the main hypothesis of this paper: member financed enforcement of compliance within stable coalitions leads to greater participation than when compliance is assured without cost. Since our theoretical development and experiments have individuals deciding whether to provide a single unit of a public good, increased participation in coalitions also implies increased provision of the good. 


\subsection{Stable coalitions without the need for costly enforcement}

Consider $n$ homogeneous players with payoff functions

$$
\pi_{i}=A+b\left(q_{i}+q_{-i}\right)-c q_{i},
$$

where $q_{i}$ is equal to one if player $i$ contributes to the public good and is zero if she does not, $q_{-i}$ is the sum of the contributions by all other players, $b$ is the constant marginal benefit of public good contributions, $c$ is the cost of contributing to the public good, and $A$ is a positive constant. The structure of the players' interactions is an $n$-player prisoners' dilemma, requiring $b<c$ and $n b>c$. That is, all players have a dominant strategy to not contribute to the public good in a noncooperative Nash equilibrium, but their joint payoffs will be maximized when they all contribute. Thus, the players have an incentive to form a cooperative agreement to provide the good.

Suppose at first that compliance with such an agreement is assured without cost. Following Ulph (2004) and Kolstad (2007), we model coalition formation as a two-stage game. In the first stage, each player decides independently whether to join a coalition to provide the public good. In the second stage, all players decide whether to contribute their unit of the good. The players that do not join the coalition in the first stage maximize their individual payoffs by not contributing to the public good in the second. Those that do join in the first stage commit to decisions in the second stage that maximize the joint payoffs of the coalition members, given that the non-members will not contribute.

The members of a coalition commit to contributing to the public good in the second stage as long as each of them is at least as well off with all members contributing as they would be if no player contributed to the public good. That is, a coalition must be profitable for its members. Let $s$ denote the number of players who join a coalition in the first stage; let $\pi^{m}(s)$ denote the 
payoff of each of the coalition members if they decide to contribute to the public good, and let $\pi^{n m}(s)$ denote the payoff of each of the non-members. (The superscript $m$ signals that the player in question is a member of the coalition, while the superscript $n m$ signals that the player is not a member of the coalition). From [1], the payoff functions for each coalition member and for each non-member are:

$$
\begin{aligned}
& \pi^{m}(s)=A+b s-c ; \\
& \pi^{n m}(s)=A+b s .
\end{aligned}
$$

Since $b<c, n b>c$, and $\pi^{m}(s)$ is increasing in $s$, there exist coalition sizes that are strictly greater than one and weakly less than $n$ that are profitable. The smallest of these profitable coalitions is

$$
s^{n c}=\min s\left|\pi^{m}(s) \geq \pi^{n m}(0)=\min s\right| s \geq c / b .
$$

Throughout, the superscript $n c$ denotes values when the decisions of the coalition members do not require costly enforcement. If $s \geq s^{n c}$ in the first stage of the game, the members of the coalition agree that each of them will contribute to the public good in the second stage. If $s<s^{n c}$, the coalition members do not contribute to the public good in the second stage.

Following D’Aspremont et al. (1983) a coalition is stable if no member of the coalition wants to leave the agreement (the coalition is internally stable) and no non-member wants to join the agreement (the agreement is externally stable). It is easy to demonstrate that in this game the only internally and externally stable coalition size is the smallest profitable coalition, $s^{\text {nc }}$. To see why, note for a coalition size $s>s^{n c}$ that any member could leave the coalition and the remaining members would still find it profitable to contribute to the public good. Using the payoff functions [2], the defector's payoff would then be $\pi^{n m}(s-1)=A+b(s-1)$, which is 
greater than its payoff if it stayed in the coalition, $\pi^{m}(s)=A+b s-c$, by the amount $c-b>0$. Since individuals are motivated to leave a coalition of any size $s>s^{n c}$, these coalitions are not internally stable. On the other hand, a coalition of size $s=s^{n c}$ is internally stable, because if one member leaves the coalition it is no longer profitable for the remaining members to contribute to the public good. Since no individual would provide the public good in this case, a defector's payoff would simply be $\pi^{n m}(0)=A$, which is weakly less than its payoff if it stayed in the coalition, $\pi^{m}\left(s^{n c}\right)=A+b s^{n c}-c$. Finally, a coalition with $s^{n c}$ members is externally stable because no non-member would want to join. To see why calculate $\pi^{m}\left(s^{n c}+1\right)-\pi^{n m}\left(s^{n c}\right)$ $=b-c<0$, which indicates that an individual who joins the smallest profitable coalition is worse off than staying out of the coalition.

Since coalitions of size $s^{\text {nc }}$ are the only internally and externally stable coalitions, the subgame perfect equilibrium of the coalition formation game is that $s^{n c}$ players join the coalition in the first stage and make their contributions to the public good in the second. The remaining players contribute nothing in the second stage of the game.

\subsection{Stable coalitions with member-financed enforcement}

We now give coalition members the opportunity to violate their commitment to provide the public good. To counteract this, coalition members fund an independent enforcer who monitors the behavior of coalition members and applies a sanction when one is found not contributing to the public good. Following McEvoy and Stranlund (2008), this game is played in four stages. In the first stage, players decide independently whether to join a cooperative coalition. In the second stage, members of the coalition jointly agree on whether to contribute to the public good. 
If they do agree to contribute to the public good, each member is required to contribute funds to the independent enforcer. If the coalition members decide not to contribute to the public good in stage 2, they do not fund the enforcer and the game ends with no contributions to the public good. If the coalition members agree to contribute to the public good in stage 2, they move onto stage 3 in which all players make their contribution decisions independently. Finally, in stage 4, the enforcer randomly audits the coalition members and applies a sanction when a member is found not contributing to the public good. Because the game is solved by backward induction we begin by describing the last stage.

\subsubsection{Enforcement stage}

If the game reaches this stage, a coalition of $s$ members has formed, each member has agreed to contribute to the public good, each member has provided $x$ dollars to fund the enforcer, and all players have made their contributions. In this stage, the enforcer randomly audits the decisions of the coalition members with a probability that is an increasing function of the amount of funding the members provide. Each additional dollar of funding allows the number of random audits to increase by $\alpha>0$. Thus, if $s$ coalition members each provide $x$ to fund the enforcer, then the number of random audits conducted is $s x \alpha$ and the probability that any member is audited is

$$
p=s x \alpha / s=x \alpha .
$$

A member that is revealed to be noncompliant by the enforcer incurs a known exogenous sanction of $f$. 


\subsubsection{Contributions stage}

At this point in the game the coalition members have agreed to contribute to the public good and have funded the enforcer. In this stage both coalition members and non-members independently choose whether to contribute to the public good. All non-members will chose to not contribute, but coalition members make this decision by comparing the expected cost of not complying with their agreement and the benefit of noncompliance.

Assume that the coalition members are risk neutral and that they comply if they are at least indifferent between compliance and noncompliance. Then, given a coalition of $s$ members, in the contributions stage an individual member will comply if its expected payoff from doing so is not less than its expected payoff from noncompliance. Given the probability of an audit $p$ and the sanction $f$, a compliant coalition member's payoff is $\pi^{m}(s)-x$, while a noncompliant member's expected payoff is $\pi^{n m}(s-1)-x-p f$, where $\pi^{m}(s)$ and $\pi^{n m}(s-1)$ are defined by [2]. Since the individuals are identical and coalition members face the same enforcement parameters, all members either comply or all do not. Therefore, each coalition member complies with the terms of the agreement if and only if

$$
\left[\pi^{m}(s)-x\right]-\left[\pi^{n m}(s-1)-x-p f\right]=p f-(c-b) \geq 0
$$

that is, each coalition member complies as long as the expected penalty $p f$ is not less than the gain from noncompliance $c-b$. Clearly, this is a necessary condition if a coalition of individuals who contribute to the public good is to form. Therefore, we will assume $p f \geq(c-b)$ from here on. 


\subsubsection{Agreement stage}

In this stage the coalition members agree to contribute to the public good and to fund the enforcer provided that these decisions maximize their joint payoffs. Each member's contribution to the enforcer, $x$, is endogenous so we determine this value first. If a coalition of contributors is to form, each member would like to contribute as little as possible while providing the enforcer with sufficient resources to maintain compliance within the coalition. This requires a payment $x$ so that $p f \geq c-b$ binds. Since $p=x \alpha$ from [4], the contribution to the enforcer that is required of each coalition member is

$$
x=(c-b) / \alpha f .
$$

Coalition members will fund the enforcer and jointly agree to contribute to the public good only if they will be at least as well off as without the coalition. Again, contributing to the public good must be profitable for the members of the coalition. Given a coalition of $s$ members that each earn $\pi^{m}(s)-x=A+b s-c-x$ if they contribute to the public good, and a player's payoff in the absence of a coalition, $A$, the minimum size profitable coalition is the smallest $s$ such that $A+b s-c-x \geq A$. Substituting for $x$ from [6] and rearranging terms yields $s \geq c / b+(c-b) / b \alpha f$. Thus, the minimum sized profitable coalition when members bear the cost of enforcing compliance within the coalition is

$$
s^{c}=\min s \mid s \geq c / b+(c-b) / b \alpha f,
$$

where the superscript $c$ indicates that enforcing compliance is costly for the members. If $s \geq s^{c}$ players join a coalition in the first stage of the game (the membership stage), they will agree to contribute to the public good in the second stage (the agreement stage). Furthermore, each member pays $x$ from [6] to the enforcer in this stage and will comply with the terms of the 
agreement in stage three (the contributions stage). On the other hand, if $s<s^{c}$ from the first stage, the coalition members maximize their joint payoffs by deciding not to contribute to the public good and they do not fund the enforcer. Thus, if $s<s^{c}$ in the membership stage a coalition of contributors to the public good does not form and the game concludes.

\subsubsection{Membership stage}

As in the coalition formation game without the need for costly enforcement, the equilibrium coalition size when member-financed enforcement is required is the smallest profitable coalition, $s^{c}$ defined by [7]. In contrast to the game in which compliance is assured, profitable coalitions may not exist when enforcement is required. Profitable coalitions exist when enforcement is required if and only if $n \geq s^{c}$, or using [7], $n \geq c / b+(c-b) / b \alpha f$. While we've assumed that $n>c / b$, there is nothing in the model that guarantees $n \geq c / b+(c-b) / b \alpha f$. Thus, a large benefit from noncompliance $c-b$, a low monitoring productivity $\alpha$, or a low sanction $f$, can prevent a coalition from forming. However, if $n \geq s^{c}$, then $s^{c}$ players will join a coalition in the first stage of the game. They will agree to contribute to the public good and fund the enforcer in the second. In the third stage they all contribute to the public good, while the non-members do not. In the fourth stage the enforcer randomly audits the decisions of the coalition members but finds no violations. This is the subgame perfect equilibrium of the coalition formation game when cooperation requires member-financed enforcement and enforcement costs do not prevent coalitions from forming. 


\subsection{Enforcement costs and size of stable coalitions}

When a coalition that requires member-financed enforcement forms, it is likely to have more members and provide more of the public good than when compliance within a coalition is enforced without cost. To see why, recall from [3] that the equilibrium coalition size when costly enforcement is not required, $s^{n c}$, is the least $s$ for which $s \geq c / b$. When a coalition requires costly enforcement and this requirement this does not prevent a coalition from forming, from [7] the equilibrium coalition size, $s^{c}$, is the least $s$ for which $s \geq c / b+(c-b) / b \alpha f$. Since $(c-b) / b \alpha f>0, s^{c} \geq s^{n c}$. The reason for this result is that funding the enforcer is an additional cost of joining a coalition to provide a public good; hence, a greater amount of the public good needs to be provided to make the coalition profitable. When each individual has one unit of the public good to contribute, this requires greater participation in the coalition. The experiments described in the next section were designed to test this hypothesis.

\section{Experimental design}

All of the experimental sessions were held in a computer lab at our university $<$ to be included $>$ using undergraduate and graduate students recruited from the general student population. The subjects were brought into the computer lab, seated and paid five dollars for arriving on time. The instructions were read aloud by the moderator. After answering a series of practice questions the subjects began the experiment. ${ }^{1}$

For each treatment, the subjects were placed in groups of $n=10$, and during each session two 10-subject groups were in the lab concurrently. At the start of each period, subjects were randomly reassigned to one of the two groups such that the same ten people were never together

\footnotetext{
${ }^{1}$ The complete experiment instructions are available at the lead author's website $<$ to be included $>$. $<$ We have included the instructions with this submission as a reviewers' appendix>
} 
in the same group more than once. The random assignment of groups was done to mitigate potential problems of reputation that can occur when the same subjects interact in a repeated setting (Andreoni and Croson 2002). Two 13-round sessions were conducted for each treatment, resulting in 52 group level observations and 520 individual level observations per treatment. Earnings were reported in experimental dollars, with ten experimental dollars exchanged for one US dollar. Earnings were paid in cash at the end of each experiment. On average the subjects earned 23 dollars, ranging from 15 to 33 dollars (standard deviation $=4.33$ dollars).

To avoid potential biases subjects may have regarding the provision of public goods, and to generalize our results to other applications of stable coalitions, we chose a neutral frame for the context and language of the experiments. Specifically, rather than having subjects decide whether to join a coalition with the others to provide a public good, they chose either to agree to produce one unit of an unspecified product, or not agree to produce the unit. An agreement was said to 'form' if enough subjects agreed to produce such that the stated participation threshold was met.

One of the unique features of our design is that while subjects were making their decisions, they were provided with real-time information about the decisions of the other nine subjects in the group. ${ }^{2}$ Specifically, they were informed about the number of other subjects that already agreed to produce, the number of other subjects that did not agree to produce and the number of other subjects that had not yet made a decision. The real-time information feature was included for two reasons. First, it best represents the timing and information of participation decisions in real cooperative coalitions (e.g., international treaties) in which agents decide when, relative to others, to join or not join. Second, the information was provided to avoid potential

\footnotetext{
${ }^{2}$ A similar real-time mechanism was introduced in the context of a voluntary contribution mechanism (VCM) by Dorsey (1992) and by Kurzban et al. (2001). To our knowledge, we are the first to include the real-time feature into threshold public good experiments.
} 
coordination problems that typically arise when decisions are made simultaneously. To cap the length of each period, subjects had 60 seconds to make their decisions. If a subject failed to decide before the time was up, she chose not agree to produce by default. Subjects were not allowed to communicate with each other in any of the treatments.

\subsection{Costless enforcement-low}

Our first treatment provides the incentives players face in the model from section 2.1 in which compliance within a cooperative coalition is costless to enforce (and therefore there was no compliance choice - those who agreed to produce automatically followed through with their agreement). For reasons that will become obvious shortly, we chose the individual cost of producing the good to be low (i.e., low $c$ ) and called this treatment costless enforcement-low. It provides a baseline to judge the effects of adding member-financed enforcement of compliance to the coalition formation game.

In each period, the only decision a subject had to make was whether to agree to produce or not agree to produce the unit. We chose parameter values of $n=10, A=8, b=3$ and $c=7$ for equation [1], and derived the theoretically stable coalition size of $s^{n c}=3$ using equation [3]. Thus, the participation threshold for costless enforcement-low was set at 3 members. If at least three of the ten group members agreed to produce, then the agreement formed and those individuals that agreed to produce automatically produced the product and earned $\pi^{m}(s)$ using [2]. If less than three group members agreed to produce, the entire group did not produce and each subject earned eight experimental dollars, $\pi^{n m}(0)=8$. Those subjects that chose not agree to produce, did not produce the product regardless of whether a coalition formed and earned $\pi^{n m}(s)$ according to [2]. 
Table 1 shows the matrix of payoff possibilities the subjects were given for each period of the experiment, the form of which is similar to that used by Rapoport and Eshed-Levy (1989). The boxes marked with an $\mathrm{X}$ indicate outcomes that are not possible because the participation threshold would not be met in these circumstances. To see why, note that the top row of the earnings table corresponds to the number of other subjects (ranging from 0 to 9) producing the good. However, production can only occur if at least three members of the group agree to produce. Therefore, under no circumstances could only one or two members of the group produce the good, hence the X's. All elements of the earnings table were clearly explained to the subjects before the experiment began.

[Insert Table 1 here]

\subsection{Costly enforcement}

Our second treatment was designed to incorporate the elements of the model of memberfinanced enforcement of compliance within a stable coalition that we presented in section 2.2. We called this treatment costly enforcement. Relative to the costless enforcement-low treatment, we added two stages to the costly enforcement treatment. Provided that enough subjects agreed to produce to meet the participation threshold, those who agreed to produce then had to decide whether to abide by this decision and actually produce. These compliance decisions were made simultaneously and without real-time feedback. After the coalition members made these decisions their choices were randomly audited and detected cases of noncompliance were sanctioned. All audits and sanctions were kept private.

The values of $n, A, b$ and $c$ were set exactly as in the costless enforcement-low treatment. In addition, we chose an audit probability of $p=0.8$ and a penalty for noncompliance of $f=6$ 
as the enforcement parameters applied to the members of a coalition. Note that the expected penalty for noncompliance was $p f=4.8$. The subjects were told the audit probability and sanction at the beginning of each period, but they were not told the expected penalty. Because the benefit from noncompliance was $c-b=4.0$, the expected penalty was more than sufficient to induce compliance by risk-neutral agents. (Refer to the condition for compliance provided by equation [5]). The cost of enforcing compliance with the agreement for each member of a coalition was set at $x=8.08$. (Using equation [6], this implies a marginal productivity of resources devoted to monitoring of $\alpha=0.619$ ). We did not have members of a coalition actually pay $x$; rather it was implicit in the calculation of their earnings.

Using [7], the stable coalition size in this treatment is six members, so the subjects were told that the participation threshold for an agreement to form was six subjects. If less than six subjects agreed to produce, the entire group did not produce and each subject earned eight experimental dollars, $\pi^{n m}(0)=8$. If six or more subjects agreed to produce, individual earnings for each possible scenario in the costly enforcement treatment are provided in Table 2. ${ }^{3}$ The subjects were given this table at the start of each period of this treatment. The second row in the table shows the potential earnings for a coalition member that complies with the agreement by choosing to produce. The third and fourth rows show earnings for a noncompliant coalition member, one who agreed to produce then chose not to. The third row gives the earnings of the subject when it is audited while the earnings in the fourth row assume the subject was not audited. The difference in earnings between these two rows is simply the $f=6$ penalty for noncompliance. The final row lists the potential earnings for a subject that does not join the coalition and, therefore, does not produce.

\footnotetext{
${ }^{3}$ The values in Table 2 are calculated earnings rounded to the nearest whole number, except for negative earnings which are set at zero to make sure that subjects did not lose money in the experiments.
} 
[Insert Table 2 here]

\subsection{Costless enforcement-high}

The third treatment is the same as the costless enforcement-low treatment except that the cost of production was increased to $c=15.08$. This higher production cost is denoted as $c_{H}$, and we refer to this treatment as costless enforcement-high. This higher cost parameter was chosen so that the increase in production cost between the costless enforcement-low treatment and the costless enforcement-high treatment is equivalent to the individual cost of enforcing compliance in the costly enforcement treatment; that is, $x=c_{H}-C=8.08$. Because of the higher production cost, the stable coalition size for the costless enforcement-high treatment is 6 members, the same stable coalition size and participation threshold as for the costly enforcement treatment. Table 3 is the payoff table we provided each subject in this treatment. Note that it takes a similar form to the earnings table for the costless enforcement-low treatment, except that more outcomes are not possible (those marked by an $\mathrm{X}$ ) because of the higher participation threshold.

[Insert Table 3 here]

Structuring the costless enforcement-high treatment so that the participation costs and the participation threshold are equivalent to that of the costly enforcement treatment allows us to isolate two effects of the compliance problem in stable coalitions. The first effect is the compliance decision itself while the second is the higher participation threshold that is associated with the additional costs of enforcing compliance within stable coalitions. Since the predicted participation levels are the same in the costless enforcement-high and the costly enforcement treatments, we can isolate the impact of the compliance decision on the performance of cooperative coalitions by comparing the results from these two treatments. Moreover, by 
comparing the results of the costless enforcement-high treatment with the costless enforcementlow treatment we can separate the effect of the higher participation cost and higher participation threshold from the compliance decision effect.

\subsection{Costly enforcement-full}

In this final treatment, we abandoned the internal and external stability conditions for determining the participation threshold and tested the performance of a coalition that requires member-financed enforcement, but also requires full participation. We call this treatment costly enforcement-full. For this treatment we maintained the same parameter choices as in the costly enforcement treatment, but we raised the participation threshold from six to ten subjects. As with the costly enforcement treatment, if the ten-subject threshold was satisfied, each member then had to decide whether to comply by producing the good. After these decisions, the coalition members were monitored and detected cases of noncompliance were sanctioned. The earnings table we provided the subjects in this treatment is the same as the one provided for the costly enforcement treatment (Table 2). A summary of our experimental design is provided in Table 4.

[Insert Table 4 here]

\section{Results}

Much of our analysis of the experimental data is based on Tables 5 and 6. For each treatment Table 5 contains the average provision of the public good, the percentage of times a coalition formed, the average number of members of coalitions, as well as the average compliance rates by members of coalitions under the costly enforcement and costly enforcement-full treatments. Table 6 contains average individual earnings when coalitions formed for members and non-members 
under the costless enforcement-low and costless enforcement-high treatments, as well as for compliant members of coalitions under the costly enforcement and costly enforcement-full treatments. We report the average expected earnings of noncompliant coalition members (gross earnings minus the 4.8 expected penalty) under these treatments. ${ }^{4}$ Our model predictions for each treatment are that coalitions form $100 \%$ of the time, the number of coalition members and the provision of the good exactly equal the participation threshold, and that coalition members are always compliant under the costly enforcement and costly enforcement-full treatments.

[Insert Table 5 here]

Recall the main hypothesis of our theoretical model of section 2: relative to stable coalitions that do not require enforcement, the possibility of noncompliance within stable coalitions and member-financed enforcement to maintain compliance results in greater participation in coalitions and, consequently, higher provision of a public good. This hypothesis is clearly rejected by our experimental data. Although the average number of members of coalitions that formed was significantly higher under the costly enforcement treatment than under the costless enforcement-low treatment as predicted (6.68 vs. 4.26, $p<0.001)$, the average provision of the public good was significantly less under the costly enforcement treatment (2.46 vs. $4.10, p=0.002) .{ }^{5}$ This occurred because coalitions formed much less frequently under the costly enforcement treatment ( $53.8 \%$ vs. $96.2 \%, p<0.001$ ), and because of the significant amount of noncompliance under this treatment. ${ }^{6}$

\footnotetext{
${ }^{4}$ We use expected, rather than actual, earnings because this is what subjects would likely be using as a basis for making decisions.

${ }^{5}$ Unless otherwise noted, all paired-comparison statistical tests are Mann-Whitney rank-sum tests and all single sample tests of predicted Nash values are Wilcoxon signed-rank tests.

${ }^{6}$ Dawes et al. (1986) found that the participation threshold was reached in $100 \%$ of trials with a low participation threshold of 3 of the 7 players. This is consistent with the $96.2 \%$ participation rate in our costless enforcement-low treatment, where the participation threshold is 3 of 10 players.
} 
The data in Table 5 indicate that the subjects under the costly enforcement treatment did not come close to meeting theoretical expectations. Although when coalitions formed they had more members than the six predicted $(6.68, p<.001)$, there was a substantial amount of noncompliance in these coalitions (31.6\%). Moreover, coalitions formed only $53.8 \%$ of the time. The high rates of noncompliance and the low frequency of coalition formation produced an average provision of the public good in this treatment of only 2.46 units, which is far below the 6 units predicted.

The low provision of the public good under the costly enforcement experiments is also reflected in the subjects’ earnings (Table 6). On average, those who joined a coalition (agreed to produce) under the costless enforcement-low treatment were better off than those who joined a coalition under the costly enforcement treatment regardless of whether the coalition members actually complied with the agreement (14.73 vs. 7.67, $p<0.001$ for compliant coalition members and 14.73 vs. 7.86, $p<0.001$ for noncompliant members). Compliant coalition members and noncompliant coalition members earned about the same under the costly enforcement treatment (7.67 vs. 7.86, $p=.499$ ), and there is no statistical difference (at the 0.05 level) between these earnings for coalition members and the 8 experimental dollars each would have earned had no coalition formed in the first place $(p=.085$ for compliant members and $p=.432$ for noncompliant members).

[Insert Table 6 here]

Recall that we conducted the costless enforcement-high experiment to separate the effect of a higher participation cost and higher participation threshold for coalitions that require member-financed enforcement from the effect of giving coalition members the opportunity to 
violate cooperative agreements. Thus, we can explain the poor performance of the costly enforcement treatment by examining the relative importance of these effects.

Note first that when coalitions formed under the costless enforcement-high treatment they contained more than the predicted number of members on average (6.19), but coalitions formed less frequently under this treatment than predicted and in comparison with the costless enforcement-low treatment (61.5\% vs. $96.2 \%, p<0.001)$. These results are consistent with several other threshold public goods studies that found that raising the participation threshold reduced the percentage of trials in which a public good is provided (Van de Kragt et al. 1983; Dawes et al. 1986; Suleimen and Rapoport 1992; Rapoport and Suleimen 1993; Cadsby and Maynes 1999). Because coalitions formed less frequently under the costless enforcement-high treatment, the average provision of the public good was significantly less than the predicted 6 units (3.81 units, $p<0.001$ ) and statistically indistinguishable from the average provision of the good under the costless enforcement-low treatment (3.81 vs. 4.10, $p=0.243$ ). Thus the higher participation cost and participation threshold had no effect on the average provision of the public good.

Now let us compare the outcomes of the costless enforcement-high treatment to the costly enforcement treatment. Coalitions formed under the costless enforcement-high treatment about as frequently as under the costly enforcement treatment (61.5\% vs. 53.8\%, $p=0.742){ }^{7}$ Although coalitions tended to have more members under the costly enforcement treatment than under the costless enforcement-high treatment (6.68 vs. 6.19, $p=0.009$ ), noncompliance under the costly

\footnotetext{
${ }^{7}$ These participation rates fall well within the typical 50 - 70\% range found in most threshold public goods experiments (Van de Kragt et al. 1983; Dawes et al. 1986; Isaac et al. 1989; Rapoport and Eshed-Levy 1989; Erev and Rapoport 1990; Suleimen and Rapoport 1992; Rapoport and Suleimen 1993; Mysker et al. 1996; Marks and Croson 1998; Marks and Croson 1999). A handful of other studies have found results that do not fall into the 50 $70 \%$ participation range, including Cadsby and Maynes (1999) who found that the public good is provided in only 26\% of pooled trials and Bagnoli and Mckee (1991) who found that the public good was provided in $83 \%$ of all trials.
} 
enforcement treatment more than offset this higher membership so that the average provision of the public good was significantly higher under the costless enforcement-high treatment (3.81 vs. 2.46, $p=0.002$ ). Thus, holding the participation costs and threshold constant, giving coalition members the opportunity to be noncompliant, but randomly auditing and fining them to maintain compliance, had a significant negative effect on the cooperative provision of the public good. Moreover, the earnings data in Table 6 indicate that the noncompliance under the costly enforcement treatment led to lower earnings. The average earnings of coalition members under the costless enforcement-high treatment were significantly higher than the earnings of the compliant coalition members under the costly enforcement treatment (11.70 vs. 7.67, $p<0.001)$ as well as the average expected earnings for noncompliant coalition members (11.70 vs. 7.86, $p$ $<0.001)$.

We are now ready to specify the relative impacts of the higher participation cost and threshold effect and the compliance decision effect on the significant underprovision of the public good under the costly enforcement treatment. Average provision of the public good under this treatment is 3.54 units below the prediction of 6 units. The higher participation cost and threshold component of these 3.54 units is the difference between the predicted 6 units and average provision under the costless enforcement-high treatment, that is, 2.19 units (about 62\% of the total effect). The compliance decision component is the remaining 1.35 units (about 38\%). Thus, the poor performance of the costly enforcement treatment relative to its theoretical prediction is explained by both the higher participation cost and threshold effect and the compliance decision effect. Moreover, the higher cost and threshold effect (2.19) is significantly greater than the compliance decision effect $(1.35, p=0.015)$, suggesting that the cost and 
threshold effect accounts for most of the underprovision of the public good under the costly enforcement treatment relative to the predicted provision of the good.

However, relative to the provision of the public good under the costless enforcement-low treatment, nearly all of the underprovision of the good under the costly enforcement treatment is due to the compliance effect. Average provision of the public good under the costly enforcement treatment is 1.64 units below average provision under the costless enforcement-low treatment. The higher participation cost and threshold component of this is the difference between the average provision of the good under the costless enforcement-low treatment and average provision under the costless enforcement-high treatment, that is, only 0.29 units. We have already noted that this difference is not statistically different from zero $(p=0.243)$. However, the compliance decision effect is the remaining 1.35 units, which is highly significant $(p=$ 0.002).

The subjects under the costly enforcement-full treatment fared much better than under the costly enforcement treatment. Recall that the costly enforcement-full treatment is exactly the same as the costly enforcement treatment, except that instead of setting the participation threshold at the theoretically stable coalition size, we required full participation for a coalition to form. Although the average compliance rate within coalitions under the costly enforcement-full treatment was not significantly different from the compliance rate under the costly enforcement treatment $(71.3 \%$ vs. $68.4 \%, p=0.471)$, coalitions formed more frequently $(88.5 \%$ of the time vs. 53.8\%, $p<.001){ }^{8}$ Consequently, the average provision of the public good was significantly higher under the costly enforcement-full treatment than under the costly enforcement treatment

\footnotetext{
${ }^{8}$ We also compared compliance decisions at the individual level between costly enforcement with costly enforcement-full by estimating a population-average, logistic regression model. The population-average model tests whether there is a significant difference in an 'average' subject's decision to comply between the two treatments with costly enforcement. We find that the average subject in both treatments is equally likely to comply, $p=.768$.
} 
(6.31 vs. 2.46, $p<0.001$ ). Not surprisingly, average payoffs for those who complied under the costly enforcement-full treatment were higher (15.46 vs. 7.67, $p<0.001$ ), as were average expected payoffs for those who did not comply (13.93 vs. 7.86, $p<0.001$ ).

To complete this section, we demonstrate that the results of the experiments are reasonably stable over the 13 rounds of each treatment. Figure 1 shows the time series of average coalition membership and average public good provision over the 13 periods in each treatment. The dark horizontal lines indicate the participation threshold for each treatment. Note that coalition membership is stable over periods for each treatment. To formally test whether coalition membership changed significantly from the beginning of each experiment to the end, we compare coalition membership between the first four periods and the last four periods for each treatment. We fail to reject the hypotheses that average coalition memberships is the same across the two time segments of the data (costless enforcement-low, $p=.5284$; costless enforcement-high, $p=.1893$; costly enforcement, $p=.1567$; costly enforcement-full, $p=.2787$ ). We do, however, note a drop in the average provision of the public good when comparing the first and last four periods under the costly enforcement treatment $(p=.0575)$, and to a lesser extent, under the costless enforcement-high treatment $(p=.0819)$.

[Insert Figure 1 here]

\section{Concluding remarks}

We have examined the compliance and enforcement problem in cooperative coalitions to provide a public good. The notion of coalitional stability that we use - that of internal and external stability—has been used in many theoretical contexts including cartels, international environmental relations and voluntary pollution control agreements between sources of pollution 
and regulators. In most of these applications, however, the rather obvious point that even cooperative arrangements must be enforced has been ignored. We have presented a theoretical model in which members of a coalition to provide a public good finance enforcement of commitments by coalition members. Our main result of this theoretical exercise is that when stable coalitions that require member-financed enforcement form they will have greater participation levels. Consequently, provision of the public good should be higher. The intuition is simple: participation in stable coalitions is higher because the added cost of enforcement must be offset by an increase in public good provision to make a cooperative coalition worthwhile.

Our laboratory test of this hypothesis is definitive-the hypothesis is flatly rejected. In experiments with member-financed enforcement when the participation threshold was set at the theoretically stable coalition size, public good provision was well below the theoretical prediction. Moreover, public good provision was below the levels obtained in a treatment that featured a participation threshold that was set at the stable coalition size, but that did not require enforcement. The lower public good provision occurred because coalitions that require enforcement formed much less frequently, and when they did form there was a significant amount of noncompliance within the coalition, even though the expected penalty was chosen to be greater than the gain from noncompliance.

Relative to stable coalitions that do not require enforcement, two things change when coalition members finance enforcement to counteract the incentive each of them has to violate their commitments. The first is the compliance decision itself and the second is the theoretical outcome that the higher participation cost leads to a higher participation threshold if coalitions with member-financed enforcement are to form. Our experimental design allows us to determine that both the compliance decision effect and the higher participation cost and threshold effect 
contributed to the poor performance of a theoretically stable coalition with member-financed enforcement.

That both of these components have significant negative impacts are puzzles that require further work to fully understand. Like us, other authors have found that increasing the participation threshold for a contract to provide a public good reduces the frequency of coalition formation and reduces the provision of a public good, but why this occurs is an open question. One possible explanation for this in our experiments is that increasing the participation threshold increases the free-riding payoffs of those who stay out of coalitions. The increased motivation to stay out of stable coalitions and perhaps a motivation to keep individuals from reaping the freeriding benefit may help explain why coalitions form less frequently with higher participation thresholds. This explanation is consistent with our finding that requiring full participation for coalitions to form significantly increased the provision of the public good, because requiring full participation eliminates the possibility of free riding by refusing to join a coalition.

The other puzzle is why there was so much noncompliance in coalitions that required enforcement, even though the expected penalty was chosen to be greater than the gain from noncompliance regardless of the size of the coalition. It is reasonable to expect, however, that more compliance can be induced with more stringent enforcement. Determining whether this should be done with more stringent monitoring or a higher penalty requires a more complete experimental analysis of the effects of monitoring and penalties on coalition formation and their performance. We should note that even if more stringent enforcement can improve the performance of theoretically stable coalitions with member-financed enforcement, our results suggest that it will not overcome the negative impact of the higher participation cost and threshold effect. 
Despite these puzzles, our results suggest important lessons for the determination of threshold rules for coalition formation and for enforcing compliance within coalitions. Although theoretically stable coalitions with member-financed enforcement did not perform well, our results, in general, highlight the need for adequate enforcement of voluntary commitments. Further, the results illustrate the importance of jointly considering enforcement mechanisms and participation requirements when considering cooperative coalitions. Improving coalition formation and compliance within coalitions may require higher participation thresholds, perhaps even full participation, and more stringent enforcement than suggested by theory. 


\section{References}

Andreoni, James and Rachel Croson, 2002. "Partners Versus Strangers: Random Rematching in Public Goods Experiments.” Prepared for Handbook of Experimental Economics Results, edited by Charles R. Plott and Vernon L. Smith.

Bagnoli, Mark and Michael McKee, 1991. "Voluntary Contributions Games: Efficient Private Provision of Public Goods.” Economic Inquiry April: 351-366.

Barrett, Scott, 1994. "Self-Enforcing International Environmental Agreements." Oxford Economic Papers 46(1): 878-94.

Cadsby, Charles Bram and Elizabeth Maynes, 1999. "Voluntary Provision of Threshold Public Goods with Continuous Contributions: Experimental Evidence.” Journal of Public Economics 71(1): 53-73.

Carraro, Carlo and Domenico Siniscalco, 1993. "Strategies for the International Protection of the Environment.” Journal of Public Economics 52(3): 309-328.

D’Aspremont, Claude; Jacquemin, Alexis; Gabszewicz, Jean Jaskold and John A. Weymark, 1983. “On the Stability of Collusive Price Leadership.” The Canadian Journal of Economics 16(1): 17-25.

Dawes, Robyn M.; Orbell, John M.; Simmons, Randy T. and Alphons J. C. Van De Kragt, 1986. “Organizing Groups for Collective Action.” The American Political Science Review 80(4): 1171-1185.

Dawson, Na Li and Kathleen Segerson. 2008. "Voluntary Agreements with Industries: Participation Incentives with Industry-wide Targets.” Land Economics 84(1): 97 - 114.

Diamantoudi, Effrosyni, 2005. “Stable Cartels Revisited.” Economic Theory 26(4): 907-921.

Dorsey, Robert E., 1992. “The Voluntary Contributions Mechanism with Real Time Revisions.” Public Choice 73(3): 261-282.

Erev, Ido and Amnon Rapoport, 1990. "Provision of Step-Level Public Goods: The Sequential Contribution Mechanism.” The Journal of Conflict Resolution 34(3): 401-425.

Isaac, Mark R.; David Schmidtz and James M. Walker, 1989. “The Assurance Problem in a Laboratory Market.” Public Choice 62(3): 217-236.

Kolstad, Charles, 2007. "Systematic Uncertainty in Self-Enforcing International Environmental Agreements.” Journal of Environmental Economics and Management 53(1): 68-79.

Kurzban, Robert; McCabe, Kevin; Smith, Vernon L. and Bart J. Wilson, 2001. "Incremental Commitment and Reciprocity in a Real-Time Public Goods Game.” Personality and Social Psychology Bulletin 27(12): 1662-1673.

Marks, Melanie and Rachel Croson, 1998. “Alternative Rebate Rules in the Provision of a Threshold Public Good: An Experimental Investigation.” Journal of Public Economics 67(2): 195-220.

Marks, Melanie and Rachel Croson, 1999. “The Effects of Incomplete Information in a Threshold Public Good Experiment.” Public Choice. 99(1-2): 103-118. 
McEvoy, David and John K. Stranlund, 2007. "Self-Enforcing International Environmental Agreements with Costly Monitoring for Compliance.” Forthcoming in Environmental and Resource Economics.

Mysker, Michael B.; Olson, Peter K. and Arlington W. Williams, 1996. "The Voluntary Provision of a Threshold Public Good: Further Experimental Results.” Research in Experimental Economics 6(1): 149-163.

Rapoport, Amnon and D. Eshed-Levy, 1989. "Provision of Step-Level Public Goods: Effects of Greed and Fear of Being Gypped.” Organizational Behavior and Human Decision Processes 44(3), 325-344.

Rapoport, Amnon and Ramzi Suleiman, 1993. "Incremental Contribution in Step-Level Public Goods Games with Asymmetric Players.” Organizational Behavior and Human Decision Processes 55(2): 171-194.

Suleiman, Ramzi and Amnon Rapoport, 1992. "Provision of Step-Level Public Goods with Continuous Contribution.” Journal of Behavioral Decision Making 5(2): 133-153.

Ulph, Alistair, 2004. "Stable International Environmental Agreements with a Stock Pollutant, Uncertainty and Learning.” Journal of Risk and Uncertainty 29(1): 53-73.

Van de Kragt, Alphons J. C.; Orbell, John M. and Robyn M. Dawes, 1983. “The Minimal Contributing Set as a Solution to Public Goods Problems.” The American Political Science Review 77(1): 112-122.

Vasconcelos, Helder, 2006. "Endogenous Mergers in Endogenous Sunk Cost Industries.” International Journal of Industrial Organization 24(2): 227-250. 
Table 1: Earnings table for costless enforcement-low

\begin{tabular}{ccccccccccc}
\hline $\begin{array}{c}\text { \# of OTHER players that } \\
\text { PRODUCE }\end{array}$ & $\mathbf{0}$ & $\mathbf{1}$ & $\mathbf{2}$ & $\mathbf{3}$ & $\mathbf{4}$ & $\mathbf{5}$ & $\mathbf{6}$ & $\mathbf{7}$ & $\mathbf{8}$ & $\mathbf{9}$ \\
\hline $\begin{array}{c}\text { YOUR earnings if you } \\
\text { produce }\end{array}$ & $\mathrm{X}$ & $\mathrm{X}$ & $\$ 10$ & $\$ 13$ & $\$ 16$ & $\$ 19$ & $\$ 22$ & $\$ 25$ & $\$ 28$ & $\$ 31$ \\
$\begin{array}{c}\text { YOUR earnings if you } \\
\text { don't produce }\end{array}$ & $\$ 8$ & $\mathrm{X}$ & $\mathrm{X}$ & $\$ 17$ & $\$ 20$ & $\$ 23$ & $\$ 26$ & $\$ 29$ & $\$ 32$ & $\$ 35$ \\
\hline
\end{tabular}

Table 2: Earnings table for costly enforcement

\begin{tabular}{cccccccccccc}
\hline & $\begin{array}{c}\text { \# of OTHER people } \\
\text { that PRODUCE }\end{array}$ & $\mathbf{0}$ & $\mathbf{1}$ & $\mathbf{2}$ & $\mathbf{3}$ & $\mathbf{4}$ & $\mathbf{5}$ & $\mathbf{6}$ & $\mathbf{7}$ & $\mathbf{8}$ & $\mathbf{9}$ \\
\hline $\begin{array}{c}\text { Agree to Produce and } \\
\text { Produce }\end{array}$ & $\$ 0$ & $\$ 0$ & $\$ 2$ & $\$ 5$ & $\$ 8$ & $\$ 11$ & $\$ 14$ & $\$ 17$ & $\$ 20$ & $\$ 23$ \\
YOUR & $\begin{array}{c}\text { Agree to Produce and } \\
\text { Don't Produce - } \\
\text { Audited } \\
\text { EARNINGS } \\
\text { if YOU: }\end{array}$ & $\$ 0$ & $\$ 0$ & $\$ 0$ & $\$ 3$ & $\$ 6$ & $\$ 9$ & $\$ 12$ & $\$ 15$ & $\$ 18$ & $\$ 21$ \\
$\begin{array}{c}\text { Agree to Produce and } \\
\text { Don't Produce - } \\
\text { Not Audited } \\
\text { Don't Agree to } \\
\text { Produce }\end{array}$ & $\$ 0$ & $\$ 3$ & $\$ 6$ & $\$ 9$ & $\$ 12$ & $\$ 15$ & $\$ 18$ & $\$ 21$ & $\$ 24$ & $\$ 27$ \\
& $\$ 0$ & $\$ 11$ & $\$ 14$ & $\$ 17$ & $\$ 20$ & $\$ 23$ & $\$ 26$ & $\$ 29$ & $\$ 32$ & $\$ 35$ \\
\hline
\end{tabular}

Table 3: Earnings table for costless enforcement-high

\begin{tabular}{ccccccccccc}
\hline $\begin{array}{c}\text { \# of OTHER players that } \\
\text { PRODUCE }\end{array}$ & $\mathbf{0}$ & $\mathbf{1}$ & $\mathbf{2}$ & $\mathbf{3}$ & $\mathbf{4}$ & $\mathbf{5}$ & $\mathbf{6}$ & $\mathbf{7}$ & $\mathbf{8}$ & $\mathbf{9}$ \\
\hline $\begin{array}{c}\text { YOUR earnings if you } \\
\text { produce }\end{array}$ & $\mathrm{X}$ & $\mathrm{X}$ & $\mathrm{X}$ & $\mathrm{X}$ & $\mathrm{X}$ & $\$ 11$ & $\$ 14$ & $\$ 17$ & $\$ 20$ & $\$ 23$ \\
$\begin{array}{c}\text { YOUR earnings if you } \\
\text { don't produce }\end{array}$ & $\$ 8$ & $\mathrm{X}$ & $\mathrm{X}$ & $\mathrm{X}$ & $\mathrm{X}$ & $\mathrm{X}$ & $\$ 26$ & $\$ 29$ & $\$ 32$ & $\$ 35$ \\
\hline
\end{tabular}


Table 4: Experimental design summary

\begin{tabular}{ccccc}
\hline Treatment & $\begin{array}{c}\text { Stable Coalition } \\
\text { Size (Participation } \\
\text { Threshold) }\end{array}$ & $\begin{array}{c}\text { Number of Subjects } \\
\text { (group size } \boldsymbol{n}=\mathbf{1 0})\end{array}$ & $\begin{array}{c}\text { Number of Group } \\
\text { Observations } \\
\text { (13 periods) }\end{array}$ & $\begin{array}{c}\text { Number of } \\
\text { Individual } \\
\text { Observations }\end{array}$ \\
\hline Costless Enforcement-Low & 3 & 40 & 52 & 520 \\
Costly Enforcement & 6 & 40 & 52 & 520 \\
Costless Enforcement-High & 6 & 40 & 52 & 520 \\
Costly Enforcement-Full & 10 & 40 & 52 & 520 \\
\hline Totals & & $\mathbf{1 6 0}$ & $\mathbf{2 0 8}$ & $\mathbf{2 , 0 8 0}$ \\
\hline
\end{tabular}

Table 5: Coalition formation, compliance, and public good provision

\begin{tabular}{|c|c|c|c|c|}
\hline Treatment & $\begin{array}{l}\text { Average provision } \\
\text { of the public good }\end{array}$ & $\begin{array}{c}\text { Percent of trials in } \\
\text { which an coalition } \\
\text { formed }\end{array}$ & $\begin{array}{c}\text { Average number of } \\
\text { members when coalition } \\
\text { formed } \\
\end{array}$ & $\begin{array}{c}\text { Percent } \\
\text { compliance }\end{array}$ \\
\hline $\begin{array}{l}\text { Costless } \\
\text { Enforcement-Low } \\
(\text { Threshold = 3) }\end{array}$ & $\begin{array}{c}4.10 \\
(0.197) \\
{[52]}\end{array}$ & $\begin{array}{c}96.2 \\
(2.69) \\
{[52]}\end{array}$ & $\begin{array}{c}4.26 \\
(.160) \\
{[50]}\end{array}$ & --- \\
\hline $\begin{array}{l}\text { Costly } \\
\text { Enforcement } \\
\text { (Threshold = 6) }\end{array}$ & $\begin{array}{c}2.46 \\
(0.342) \\
{[52]}\end{array}$ & $\begin{array}{c}53.8 \\
(6.98) \\
{[52]}\end{array}$ & $\begin{array}{c}6.68 \\
(.179) \\
{[28]}\end{array}$ & $\begin{array}{l}68.4 \\
(3.4) \\
{[187]}\end{array}$ \\
\hline $\begin{array}{l}\text { Costless } \\
\text { Enforcement-High } \\
(\text { Threshold = 6) }\end{array}$ & $\begin{array}{c}3.81 \\
(0.425) \\
{[52]}\end{array}$ & $\begin{array}{c}61.5 \\
(6.81) \\
{[52]}\end{array}$ & $\begin{array}{c}6.19 \\
(.095) \\
{[32]}\end{array}$ & --- \\
\hline $\begin{array}{l}\text { Costly } \\
\text { Enforcement-Full } \\
(\text { Threshold = 10) }\end{array}$ & $\begin{array}{c}6.31 \\
(0.382) \\
{[52]}\end{array}$ & $\begin{array}{c}88.5 \\
(4.47) \\
{[52]}\end{array}$ & $\begin{array}{c}10 \\
--- \\
{[46]}\end{array}$ & $\begin{array}{l}71.3 \\
(2.1) \\
{[460]}\end{array}$ \\
\hline
\end{tabular}

Standard errors in parentheses, number of observations in brackets. 


\section{Table 6: Average expected earnings when coalitions formed}

\begin{tabular}{lcc}
\hline \multicolumn{1}{c}{ Treatment / Player Decision } & Frequency & $\begin{array}{c}\text { Average Period } \\
\text { Earnings }\end{array}$ \\
\hline Costless Enforcement-Low & & \\
$\quad$ Agree to produce (Coalition members) & 213 & $14.73(3.73)$ \\
$\quad$ Do not agree to produce (Non-members) & 287 & $20.07(3.12)$ \\
Costly Enforcement & & \\
$\quad$ Agree to produce - produce (Compliant coalition members) & 128 & $7.67(3.92)$ \\
$\quad$ Agree to produce - not produce (Noncompliant coalition members) & 59 & $7.86(3.20)$ \\
$\quad$ Do not agree to produce (Non-members) & 93 & $21.06(3.15)$ \\
Costless Enforcement-High & & \\
$\quad$ Agree to produce (Coalition members) & 198 & $11.70(1.75)$ \\
$\quad$ Do not agree to produce (Non-members) & 122 & $26.24(1.23)$ \\
Costly Enforcement-Full & & \\
$\quad$ Agree to produce - produce (Compliant coalition members) & 328 & $15.46(4.52)$ \\
Agree to produce - not produce (Noncompliant coalition members) & 132 & $13.93(4.42)$ \\
\hline
\end{tabular}

Earnings reported in experimental dollars, standard deviations in parentheses. In all treatments, all subjects earned \$8 if a coalition did not form. 


\section{Reviewers’' Appendix}
A. Experiment instructions - costless enforcement-low

\section{Experiment Instructions}

Thank you for agreeing to participate in this experiment. The instructions are fairly simple, and if you follow them carefully you may earn a considerable amount of money which will be paid to you in CASH at the end of the experiment. The exact amount of money you will earn will depend on your decisions, and the decisions made by the other participants, during this experiment.

\section{GENERAL DETAILS}

Please follow along while I read these instructions out loud. At times I will ask you to look up at the Power Point display at the front of the classroom. After I have completed reading through these instructions, a multiple period experiment will begin. The experiment will be run on the computer monitor at your station and you will use the mouse to make all of your decisions. Please do not talk to each other or move around during this experiment! Please make sure all cell phones and other personal electronic equipment are switched off.

Throughout this session, your earnings will be reported in experimental dollars. 10 Experimental Dollars equals 1 US dollar. Your earnings, in US dollars, will be paid to you at the end of the experiment in cash.

\section{YOUR DECISIONS}

During each period of this experiment you have the opportunity to earn money by deciding whether or not to produce one unit of an unspecified product. There will be 13 periods.

You will be in a group with 9 OTHER members each of whom will be presented with the same choices. The group assignments will change after every period. You will not be matched up with the same other 9 people for more than a single period.

The exact amount of money you will earn will depend on YOUR decisions as well as the decisions of the OTHER members in your group. Likewise, YOUR decisions will affect the earnings of the OTHER members in your group.

\section{THE AGREEMENT}

Before any production decisions are actually made, in each period you must decide whether or not you are willing to join an agreement with the other members in your group. You and the other 9 members of your group will choose either to agree to produce or not agree to produce one unit of the product. 


\section{WHAT AGREE TO PRODUCE AND NOT AGREE TO PRODUCE MEAN}

Choosing agree to produce means you are willing to join an agreement with the other members in your group. The agreement will only form if at least $\underline{\mathbf{3}}$ group members in total choose agree to produce, otherwise the agreement will not form.

- If the agreement forms:

Those that agreed to produce automatically produce the product. Those that did not agree to produce automatically do not produce the product.

- If the agreement does not form:

Each person in the group does not produce the product, the period ends and each person earns 8 Experimental Dollars.

- Choosing to not agree to produce means you will not produce the product, regardless if the agreement forms.

To recap, once each person in your group has made his/her decision to agree or not agree to produce, one of two things can happen:

(1) If $\underline{\mathbf{3}}$ or more members of the group chose agree to produce then those that agreed to produce automatically produce the product. Those that did not agree to produce automatically do not produce the product.

(2) If less than $\underline{3}$ members in the group chose agree to produce then the period ends and ALL members of the group automatically do not produce the product and each person earns 8 Experimental Dollars.

[ARE THERE ANY QUESTIONS SO FAR?] 


\section{YOUR EARNINGS}

Recall, if the agreement does not form, ALL people in the group do not produce the product and each member earns 8 Experimental Dollars. At that point the period ends.

The Earnings Table, provided below, shows your earnings for each possible outcome when the agreement forms. This is the exact table you will be given on your computer monitor.

\section{Earnings Table}

\begin{tabular}{|l|r|r|r|r|r|r|r|r|r|r|}
\hline $\begin{array}{l}\text { \# of OTHER } \\
\text { players that } \\
\text { PRODUCE }\end{array}$ & 0 & 1 & 2 & 3 & 4 & 5 & 6 & 7 & 8 & 9 \\
\hline $\begin{array}{l}\text { YOUR earnings if you } \\
\text { PRODUCE }\end{array}$ & $\times$ & $\times$ & $\$ 10$ & $\$ 13$ & $\$ 16$ & $\$ 19$ & $\$ 22$ & $\$ 25$ & $\$ 28$ & $\$ 31$ \\
\hline $\begin{array}{l}\text { YOUR earnings if you } \\
\text { DON'T PRODUCE }\end{array}$ & $\$ 8$ & $\times$ & $\times$ & $\$ 17$ & $\$ 20$ & $\$ 23$ & $\$ 26$ & $\$ 29$ & $\$ 32$ & $\$ 35$ \\
\hline
\end{tabular}

The bottom two rows of the table list your two choices and potential earnings. Notice that your information is all in black. The top row indicates the number of other people in your group producing the product (ranging from 0 to 9 people). Notice that the information pertaining to the other members in your group is all in blue.

The boxes marked with $X$ s indicate impossible outcomes. Recall, in order for any production to occur, at least 3 people in your group must agree to produce. Therefore, the two scenarios that can exist are:

- If less than $\underline{\mathbf{3}}$ people agree to produce, zero people will produce and each person in the group earns 8 Experimental Dollars.

- $\quad$ If $\underline{\mathbf{3}}$ or more people agree to produce, all those that agree actually produce the product.

To get a feel for how the table works, let's go through two examples:

Example 1: Suppose that all the other people in your group have made their decisions.

Specifically, 4 other people chose agree to produce. First note that because 3 or more people in total agreed to produce, the agreement has formed. Given this:

- If you chose agree to produce you would earn 16 experimental dollars (\$1.60 US). 
- If you chose to not agree to produce, you would earn 20 experimental dollars (\$2.00 US).

Example 2: Suppose that all the other people in your group have made their decisions. Specifically, 2 other people chose agree to produce. Given this:

- If you chose agree to produce, the agreement would form and you would earn 10 Experimental Dollars.

- If you chose to not agree to produce, the agreement would not form and you would earn 8 Experimental Dollars.

\section{HOW THE EXPERIMENT WORKS}

Once we have finished reading the instructions you will begin the experiment. To do so, you must click the green "READY TO START" button in the top right corner of your screen.

Once each member of your group has clicked the button, the first period will begin.

The image below is an example of the first screen that will appear during each period of play. Notice that the I agree to produce and I do not agree to produce buttons are in the center-left area of the screen. Once any person in the group makes a decision, the buttons become inactive for 1 second in order to notify the entire group that a decision has been made.

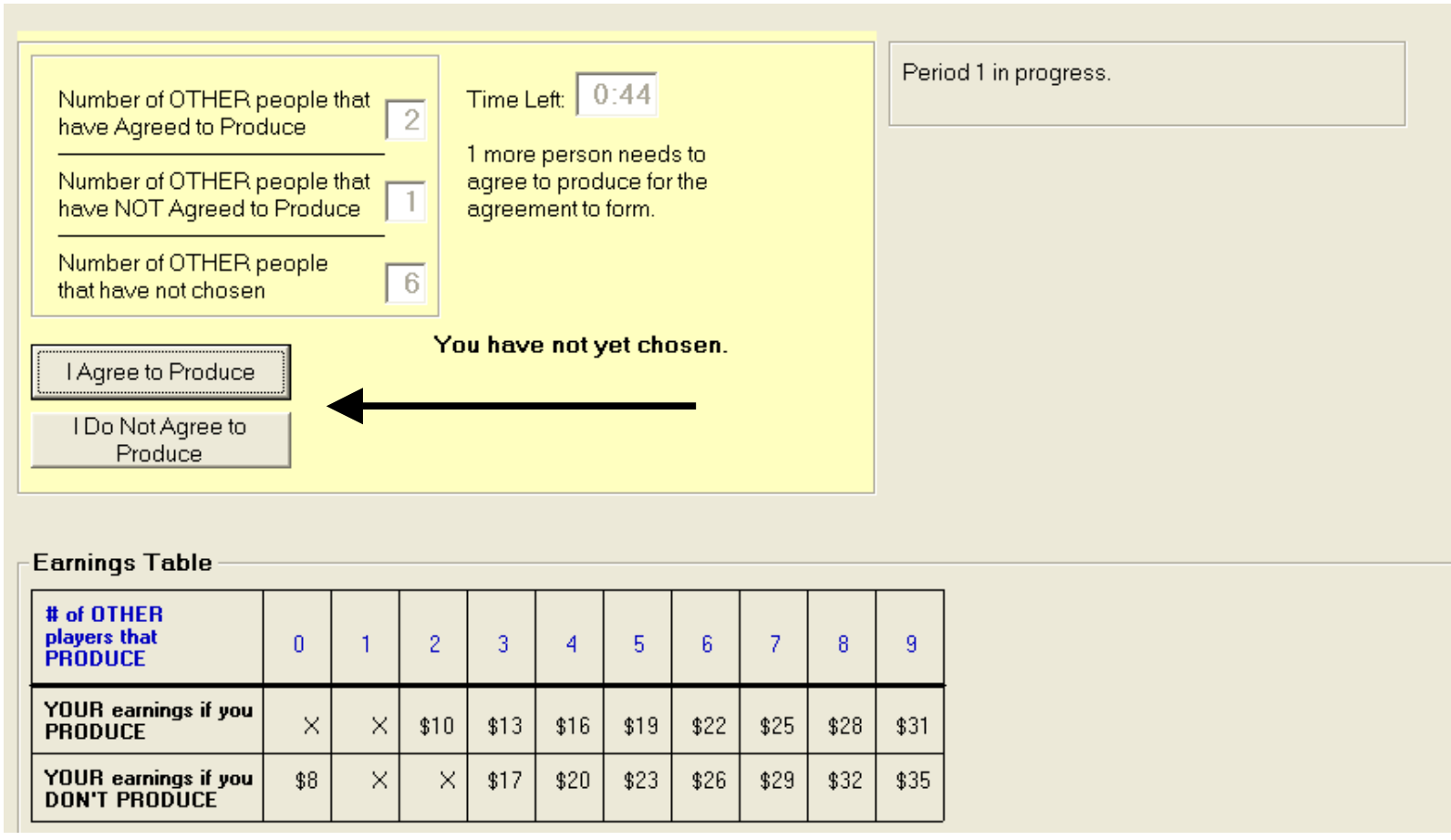


Notice also that you only have a limited amount of time to make your decision. The clock in the top area of the screen will indicate the time remaining. Also in the upper left area are boxes indicating the number of other members of the group who have agreed to produce, the number who did not agree to produce and the number of people who have not yet chosen. When you or another member in your group makes a decision, the corresponding box in the upper left area will quickly flash yellow.

In the example screen shot above, 2 other people have agreed to produce, 1 other person has not agreed to produce and 6 other people have not yet chosen. [Please now look up at the PowerPoint Display]

If at anytime the agreement forms ( $\underline{3}$ or more people agreed to produce), the screen will display that the agreement has formed.

Once each member of the group has made their decision OR the time on the clock has run out, Stage 1 will be over. Those who did not make a decision by the time the clock runs out will be automatically counted as NOT agreeing to produce. At that point, a message box will pop-up indicating whether or not the agreement has formed.

\section{END OF PERIOD}

After all groups have finished making their decisions, the period will be over. At that point a Period Results box will appear at the bottom of your monitor displaying the period outcomes, your earnings for the period and your cumulative earnings thus far. An example of the Period Results Box is shown below.

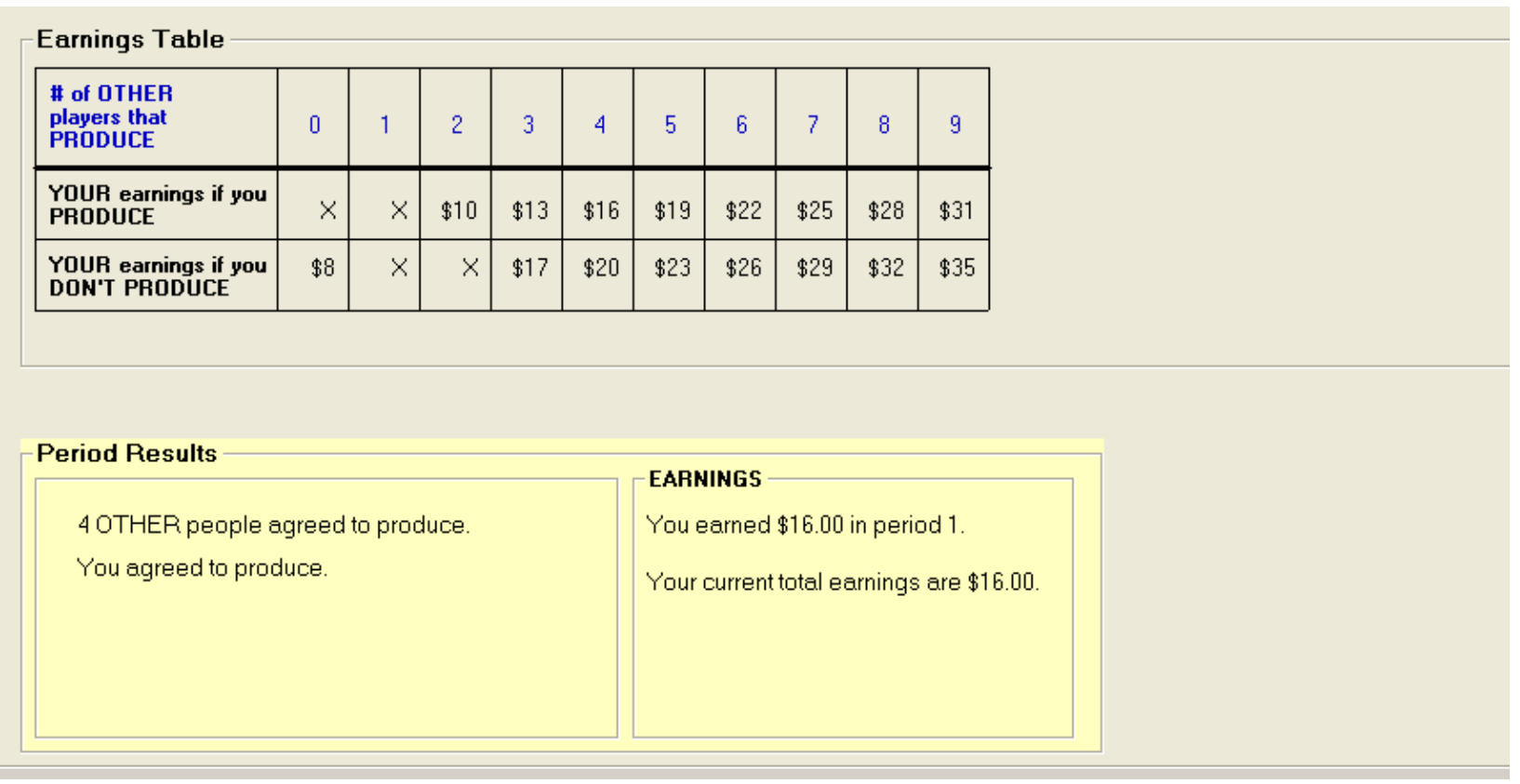


In the example Period Results Table above, a total of 5 people agreed to produce. Because 3 or more players agreed to produce, the agreement did form. A summary of the period and total earnings is also provided in the right-hand side of the box. [Please now look up at the PowerPoint Display]

Once you have had a chance to look at the Period Results you can click the green "Ready to Start" button at the top of the screen to begin the next period. Once all groups are ready, the next period will begin immediately.

\section{END OF EXPERIMENT}

The experiment will have 13 periods. You will be notified on your computer monitor once the experiment has ended and a summary screen with your total earnings will be displayed. At that point please stay seated and quiet and wait for your earnings to be paid to you.

\section{SUMMARY}

- During each period of play you choose either to agree to produce OR not agree to produce.

- If the agreement forms, those who agreed to produce automatically produce the product and those who did not agree to produce automatically do not produce the product. If the agreement does not form, ALL members of the group do not produce and the period ends. Each person earns 8 Experimental Dollars.

- If the agreement forms, the exact amount of money you earn each period is determined both by your choice and the choices made by the other members in your group. The

Earnings Table if the Agreement Forms on your screen displays all of your earning possibilities.

- 10 Experimental Dollars = 1 U.S. Dollar. Fractions of a dollar will be rounded up to the nearest quarter.

- This experiment has 13 periods. You will not be matched up with the same 9 people for more than 1 period.

- Once the experiment has finished, please remain seated until you have received your earnings. THANKS!

Once the green "Ready to Start" button becomes active, you can click this button to begin the experiment. 


\section{B. Experiment instructions - costless enforcement-high}

\section{Experiment Instructions}

Thank you for agreeing to participate in this experiment. The instructions are fairly simple, and if you follow them carefully you may earn a considerable amount of money which will be paid to you in CASH at the end of the experiment. The exact amount of money you will earn will depend on your decisions, and the decisions made by the other participants, during this experiment.

\section{GENERAL DETAILS}

Please follow along while I read these instructions out loud. At times I will ask you to look up at the Power Point display at the front of the classroom. After I have completed reading through these instructions, a multiple period experiment will begin. The experiment will be run on the computer monitor at your station and you will use the mouse to make all of your decisions. Please do not talk to each other or move around during this experiment! Please make sure all cell phones and other personal electronic equipment are switched off.

Throughout this session, your earnings will be reported in experimental dollars. 10 Experimental Dollars equals 1 US dollar. Your earnings, in US dollars, will be paid to you at the end of the experiment in cash.

\section{YOUR DECISIONS}

During each period of this experiment you have the opportunity to earn money by deciding whether or not to produce one unit of an unspecified product. There will be 13 periods.

You will be in a group with 9 OTHER members each of whom will be presented with the same choices. The group assignments will change after every period. You will not be matched up with the same other 9 people for more than a single period.

The exact amount of money you will earn will depend on YOUR decisions as well as the decisions of the OTHER members in your group. Likewise, YOUR decisions will affect the earnings of the OTHER members in your group.

\section{THE AGREEMENT}

Before any production decisions are actually made, in each period you must decide whether or not you are willing to join an agreement with the other members in your group. You and the other 9 members of your group will choose either to agree to produce or not agree to produce one unit of the product. 


\section{WHAT AGREE TO PRODUCE AND NOT AGREE TO PRODUCE MEAN}

Choosing agree to produce means you are willing to join an agreement with the other members in your group. The agreement will only form if at least $\underline{\mathbf{6}}$ group members in total choose agree to produce, otherwise the agreement will not form.

- If the agreement forms:

Those that agreed to produce automatically produce the product. Those that did not agree to produce automatically do not produce the product.

- If the agreement does not form:

Each person in the group does not produce the product, the period ends and each person earns 8 Experimental Dollars.

- Choosing to not agree to produce means you will not produce the product, regardless if the agreement forms.

To recap, once each person in your group has made his/her decision to agree or not agree to produce, one of two things can happen:

(1) If $\underline{\mathbf{6}}$ or more members of the group chose agree to produce then those that agreed to produce automatically produce the product. Those that did not agree to produce automatically do not produce the product.

(2) If less than $\underline{\mathbf{6}}$ members in the group chose agree to produce then the period ends and ALL members of the group automatically do not produce the product and each person earns 8 Experimental Dollars.

\section{[ARE THERE ANY QUESTIONS SO FAR?]}




\section{YOUR EARNINGS}

Recall, if the agreement does not form, ALL people in the group do not produce the product and each member earns 8 Experimental Dollars. At that point the period ends.

The Earnings Table, provided below, shows your earnings for each possible outcome when the agreement forms. This is the exact table you will be given on your computer monitor.

\section{Earnings Table}

\begin{tabular}{|l|r|r|r|r|r|r|r|r|r|r|}
\hline $\begin{array}{l}\text { \# of OTHER } \\
\text { players that } \\
\text { PRODUCE }\end{array}$ & 0 & 1 & 2 & 3 & 4 & 5 & 6 & 7 & 8 & 9 \\
\hline $\begin{array}{l}\text { YOUR earnings if you } \\
\text { PRODUCE }\end{array}$ & $\times$ & $\times$ & $\times$ & $\times$ & $\times$ & $\$ 11$ & $\$ 14$ & $\$ 17$ & $\$ 20$ & $\$ 23$ \\
\hline $\begin{array}{l}\text { YOUR earnings if you } \\
\text { DON'T PRODUCE }\end{array}$ & $\$ 8$ & $\times$ & $\times$ & $\times$ & $\times$ & $\times$ & $\$ 26$ & $\$ 29$ & $\$ 32$ & $\$ 35$ \\
\hline
\end{tabular}

The bottom two rows of the table list your two choices and potential earnings. Notice that your information is all in black. The top row indicates the number of other people in your group producing the product (ranging from 0 to 9 people). Notice that the information pertaining to the other members in your group is all in blue.

The boxes marked with $X$ s indicate impossible outcomes. Recall, in order for any production to occur, at least 6 people in your group must agree to produce. Therefore, the two scenarios that can exist are:

- If less than $\underline{\mathbf{6}}$ people agree to produce, zero people will produce and each person in the group earns 8 Experimental Dollars.

- If $\underline{\mathbf{6}}$ or more people agree to produce, all those that agree 'actually' produce the product.

To get a feel for how the table works, let's go through two examples:

Example 1: Suppose that all the other people in your group have made their decisions.

Specifically, 7 other people chose agree to produce. First note that because 6 or more people in total agreed to produce, the agreement has formed. Given this:

- If you chose agree to produce you would earn 17 experimental dollars (\$1.70 US).

- If you chose to not agree to produce, you would earn 29 experimental dollars (\$2.90 US). 
Example 2: Suppose that all the other people in your group have made their decisions. Specifically, 5 other people chose agree to produce. Given this:

- If you chose agree to produce, the agreement would form and you would earn 11 Experimental Dollars.

- If you chose to not agree to produce, the agreement would not form and you would earn 8 Experimental Dollars.

\section{HOW THE EXPERIMENT WORKS}

Once we have finished reading the instructions you will begin the experiment. To do so, you must click the green "READY TO START" button in the top right corner of your screen.

Once each member of your group has clicked the button, the first period will begin.

The image below is an example of the first screen that will appear during each period of play. Notice that the I agree to produce and I do not agree to produce buttons are in the center-left area of the screen. Once any person in the group makes a decision, the buttons become inactive for 1 second in order to notify the entire group that a decision has been made.

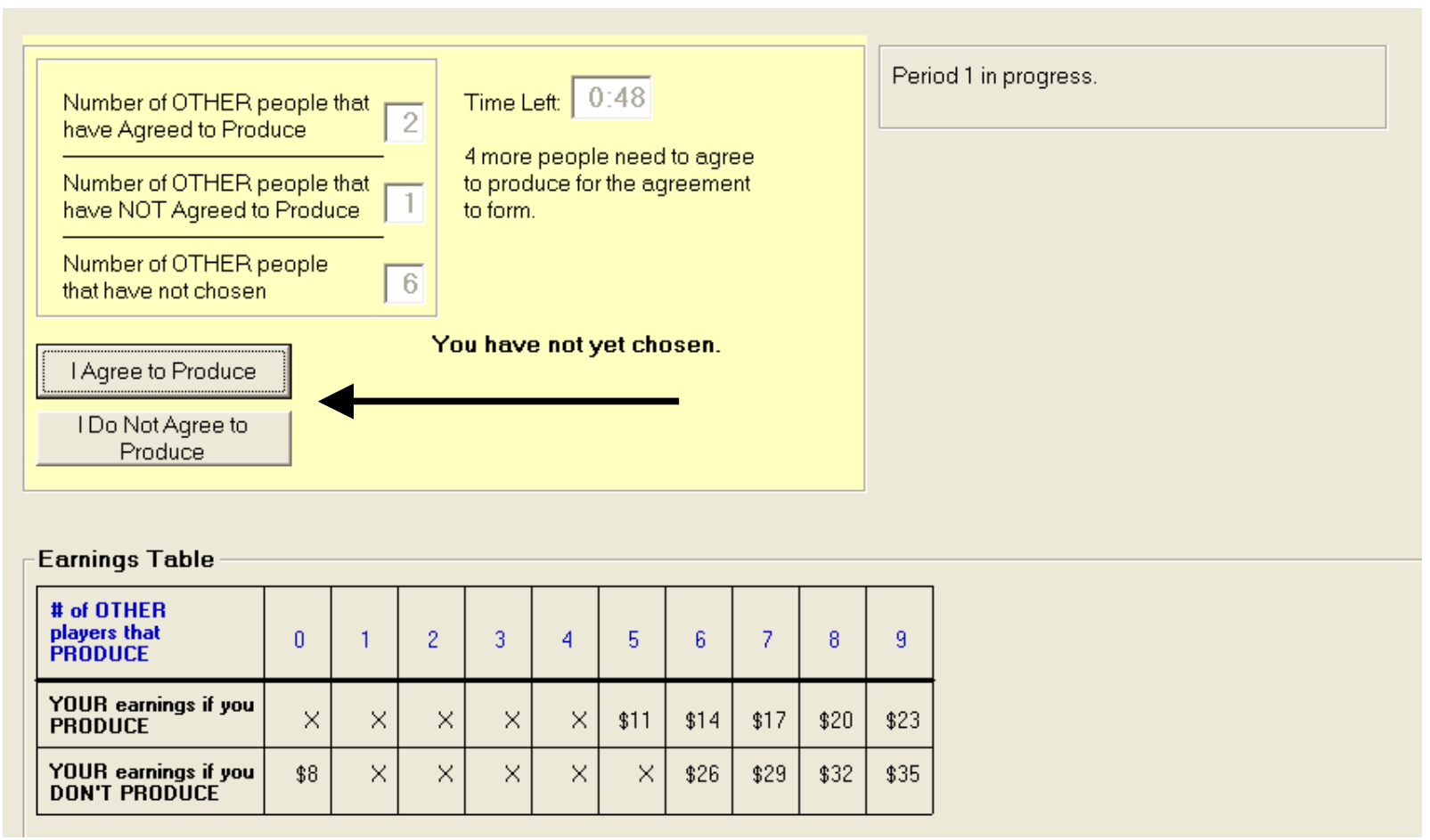

Notice also that you only have a limited amount of time to make your decision. The clock in the top area of the screen will indicate the time remaining. Also in the upper left area are boxes 
indicating the number of other members of the group who have agreed to produce, the number who did not agree to produce and the number of people who have not yet chosen. When you or another member in your group makes a decision, the corresponding box in the upper left area will quickly flash yellow.

In the example screen shot above, 2 other people have agreed to produce, 1 other person has not agreed to produce and 6 other people have not yet chosen. [Please now look up at the PowerPoint Display]

If at anytime the agreement forms ( $\underline{\mathbf{6}}$ or more people agreed to produce), the screen will display that the agreement has formed.

Once each member of the group has made their decision OR the time on the clock has run out, the period will be over. Those who did not make a decision by the time the clock runs out will be automatically counted as NOT agreeing to produce. At that point, a message box will pop-up indicating whether or not the agreement has formed.

\section{END OF PERIOD}

After all groups have finished making their decisions, the period will be over. At that point a Period Results box will appear at the bottom of your monitor displaying the period outcomes, your earnings for the period and your cumulative earnings thus far. An example of the Period Results Box is shown below. 


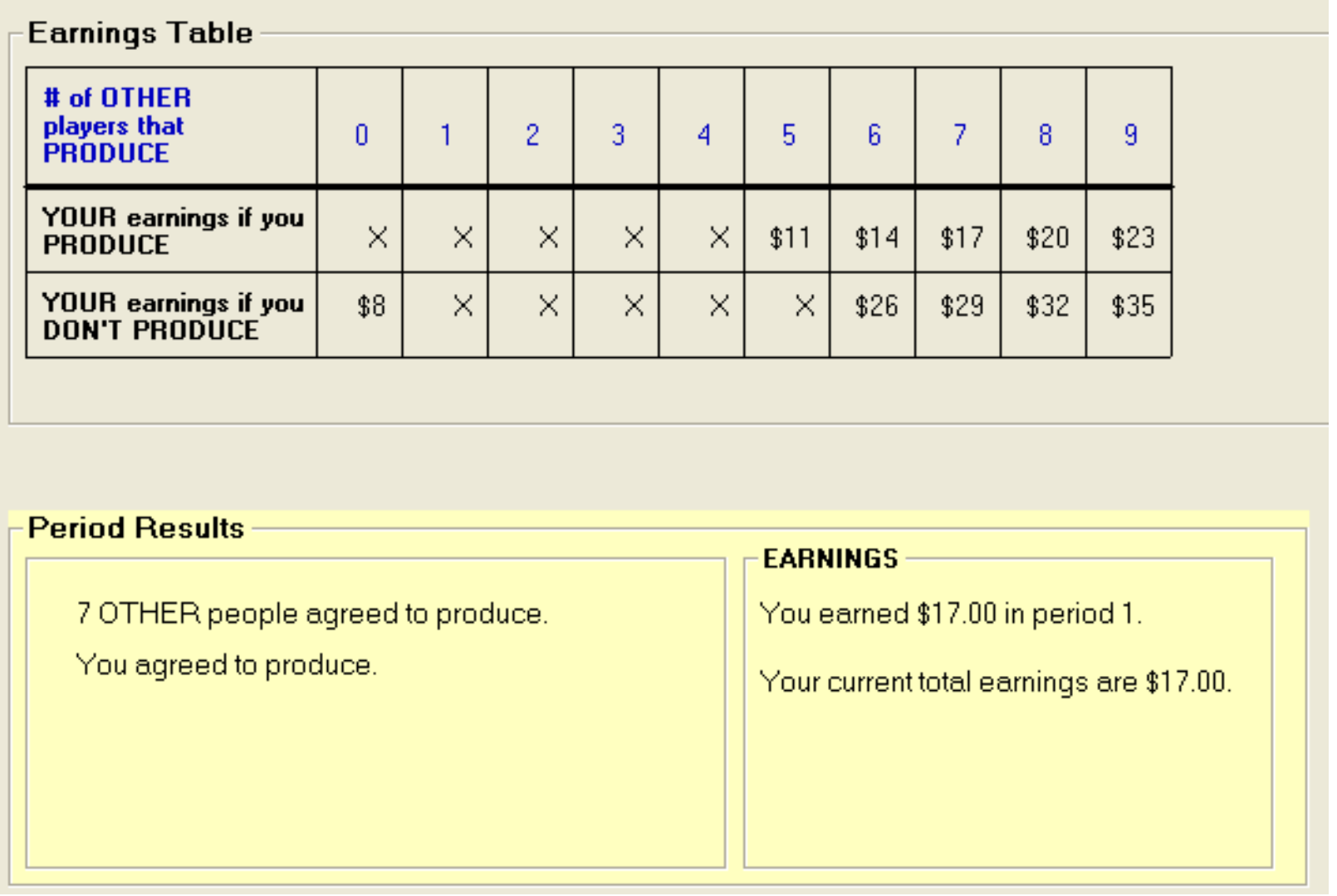

In the example Period Results Table above, a total of 8 people agreed to produce. Because 6 or more players agreed to produce, the agreement did form. A summary of the period and total earnings is also provided in the right-hand side of the box. [Please now look up at the PowerPoint Display]

Once you have had a chance to look at the Period Results you can click the green "Ready to Start" button at the top of the screen to begin the next period. Once all groups are ready, the next period will begin immediately.

END OF EXPERIMENT

The experiment will have 13 periods. You will be notified on your computer monitor once the experiment has ended and a summary screen with your total earnings will be displayed. At that point please stay seated and quiet and wait for your earnings to be paid to you.

\section{SUMMARY}

- During each period of play you choose either to agree to produce OR not agree to produce. 
- If the agreement forms, those who agreed to produce automatically produce the product and those who did not agree to produce automatically do not produce the product. If the agreement does not form, ALL members of the group do not produce and the period ends. Each person earns 8 Experimental Dollars.

- If the agreement forms, the exact amount of money you earn each period is determined both by your choice and the choices made by the other members in your group. The Earnings Table if the Agreement Forms on your screen displays all of your earning possibilities.

- 10 Experimental Dollars = 1 U.S. Dollar. Fractions of a dollar will be rounded up to the nearest quarter.

- This experiment has 13 periods. You will not be matched up with the same 9 people for more than 1 period.

- Once the experiment has finished, please remain seated until you have received your earnings. THANKS!

Once the green "Ready to Start" button becomes active, you can click this button to begin the experiment. 
C. Experiment instructions - costly enforcement

\section{Experiment Instructions}

Thank you for agreeing to participate in this experiment. The instructions are fairly simple, and if you follow them carefully you may earn a considerable amount of money which will be paid to you in CASH at the end of the experiment. The exact amount of money you will earn will depend on your decisions, and the decisions made by the other participants, during this experiment.

\section{GENERAL DETAILS}

Please follow along while I read these instructions out loud. At times I will ask you to look up at the Power Point display at the front of the classroom. After I have completed reading through these instructions, a multiple period experiment will begin. The experiment will be run on the computer monitor at your station and you will use the mouse to make all of your decisions.

Please do not talk to each other or move around during this experiment! Please make sure all cell phones and other personal electronic equipment are switched off.

Throughout this session, your earnings will be reported in experimental dollars. 10 Experimental Dollars equals 1 US dollar. Your earnings, in US dollars, will be paid to you at the end of the experiment in cash.

\section{YOUR DECISIONS}

During each period of this experiment you have the opportunity to earn money by deciding whether or not to produce one unit of an unspecified product. There will be 13 periods.

You will be in a group with 9 OTHER members each of whom will be presented with the same choices. The group assignments will change after every period. You will not be matched up with the same other 9 people for more than a single period.

The exact amount of money you will earn will depend on YOUR decisions as well as the decisions of the OTHER members in your group. Likewise, YOUR decisions will affect the earnings of the OTHER members in your group.

\section{STAGE 1}

Before any production decisions are actually made, in Stage 1 of each period you first must decide whether or not you are willing to join an agreement with the other members in your group. You and the other 9 members of your group will choose either to agree to produce or not agree to produce one unit of the product. 


\section{WHAT AGREE TO PRODUCE AND NOT AGREE TO PRODUCE MEAN}

Choosing agree to produce means you are willing to join an agreement with the other members in your group. The agreement will only form if at least $\underline{\mathbf{6}}$ group members in total choose agree to produce, otherwise the agreement will not form.

- If the agreement forms:

Those that joined the agreement then move onto Stage 2. Those that move onto Stage 2 will have the opportunity to 'comply' with what they agreed to. That is, in Stage 2 they are given the opportunity to either produce or not produce.

- If the agreement does not form:

Each person in the group does not produce the product, the period ends and each person earns 8 Experimental Dollars.

- Choosing to not agree to produce means you will not produce the product, regardless if the agreement forms.

To recap, once each person in your group has made his/her decision to agree or not agree to produce, one of two things can happen:

(1) If $\underline{\mathbf{6}}$ or more members of the group chose agree to produce then only those who agreed to produce move onto Stage 2. Those who move onto Stage 2 are given the opportunity to produce or not produce. Those that did not agree to produce automatically do not produce the product and must wait for others to make their decisions in Stage 2.

(2) If less than $\underline{\mathbf{6}}$ members in the group chose agree to produce then the period ends and ALL members of the group automatically do not produce the product and each person earns 8 Experimental Dollars.

[ARE THERE ANY QUESTIONS SO FAR?] 


\section{STAGE 2}

To reiterate, if the agreement forms, those who agreed to produce will have the opportunity to comply with the decision they made in Stage 1. That is, they can choose either to produce or not produce in Stage 2.

The decisions made in Stage 2 will be audited with a probability of .8. Meaning, there is an $80 \%$ chance each person in the group is audited and a $20 \%$ chance each person in the group is not audited. Those people who are audited and who chose not produce will be fined $\mathbf{6}$

Experimental Dollars. People who are audited and chose produce, or are not audited, will not be fined.

[Flip to next page] 


\section{YOUR EARNINGS}

Recall, if the agreement does not form, ALL people in the group do not produce the product and each member earns 8 Experimental Dollars. At that point the period ends.

The Earnings Table if the Agreement Forms, provided below, shows your earnings for each possible outcome when the agreement forms. This is the exact table you will be given on your computer monitor.

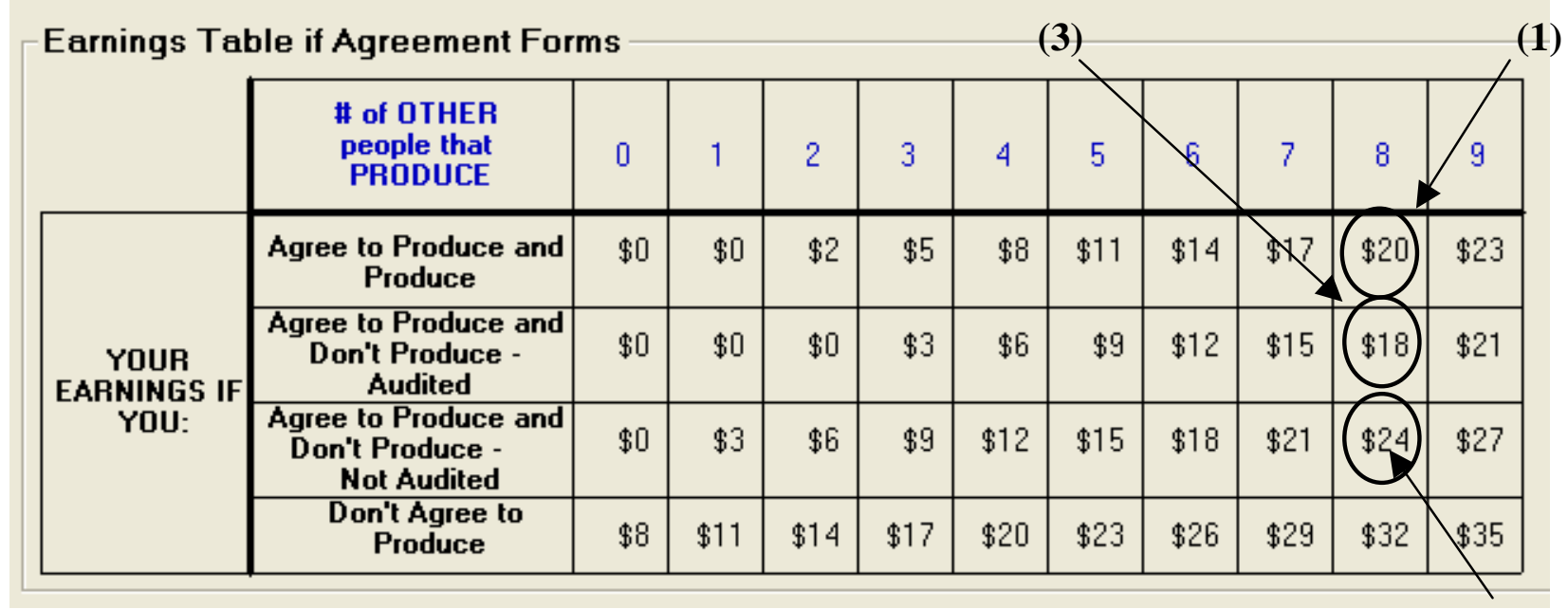

The bottom four rows of the table list your four possible choices and potential earnings. Notice that your information is all in black. The top row of the table lists the number of other members in your group choosing to produce ( 0 to 9 people). Notice that the information pertaining to the other members in your group is in blue. [Please now look up at the PowerPoint Display]

To get a feel for how the table works, let’s go through a few examples:

Example 1: Suppose all 10 members of the group agreed to produce in Stage 1. Therefore, the agreement forms because at least 6 people have agreed to produce and every member of the group moves onto Stage 2. In Stage 2, suppose that 8 other people in your group chose to produce and 1 other person chose to not produce. Given this, your period earnings would be one of the following:

(1) If you chose to produce in Stage 2, you would earn 20 Experimental Dollars.

(2) If you chose not produce in Stage 2 and WERE NOT audited, you would earn 24 Experimental Dollars.

(3) If you chose not produce in Stage 2 and WERE audited, you would be charged a penalty of 6 and therefore you would earn 18 Experimental Dollars. 


\section{Note that each of these scenarios is numbered on the table above.}

Example 2: Suppose only 4 other members in your group agreed to produce by the end of Stage 1. In this case, the agreement does not form and ALL members of the group do not produce the product, the period ends and each member earns 8 Experimental Dollars.

Practice Questions: Please follow along as I read the following practice questions. For each question, fill in the blank with the correct answer. After you have had a chance to answer the questions, I will then go over the answers.

Question 1: Suppose you have not yet made your decision whether or not to agree to produce in Stage 1. Also assume that the other 9 members of your group have all made their decisions. Specifically, 5 other people have agreed to produce and 4 other people have not agreed to produce.

- Given the choices made by your group members, if you chose to agree to produce would the agreement form $(\mathrm{Y} / \mathrm{N})$ ?

- Given the choices made by your group members, if you chose to NOT agree to produce would the agreement form $(\mathrm{Y} / \mathrm{N})$ ? . How many Experimental Dollars would you earn in this case?

Please now look up at the PowerPoint Display

Question 2: Suppose you and 8 other members of your group agreed to produce in Stage 1. Once in Stage 2, what would your experimental earnings be if:

- 7 other group members chose to produce, 1 chose not to produce and you chose to produce?

- 7 other group members chose to produce, 1 chose not to produce and you chose not to produce and were NOT audited?

- 7 other group members chose to produce, 1 chose not to produce and you chose not to produce and were audited?

Please now look up at the PowerPoint Display

\section{HOW THE EXPERIMENT WORKS}

Once we have finished reading the instructions you will begin the experiment. To do so, you must click the green "READY TO START" button in the top right corner of your screen.

Once each member of your group has clicked the button, the first period will begin. 


\section{STAGE 1}

The image below is an example of the first screen that will appear during each period of play. Notice that the I agree to produce and I do not agree to produce buttons are in the center-left area of the screen. Once any person in the group makes a decision, the buttons become inactive for 1 second in order to notify the entire group that a decision has been made.

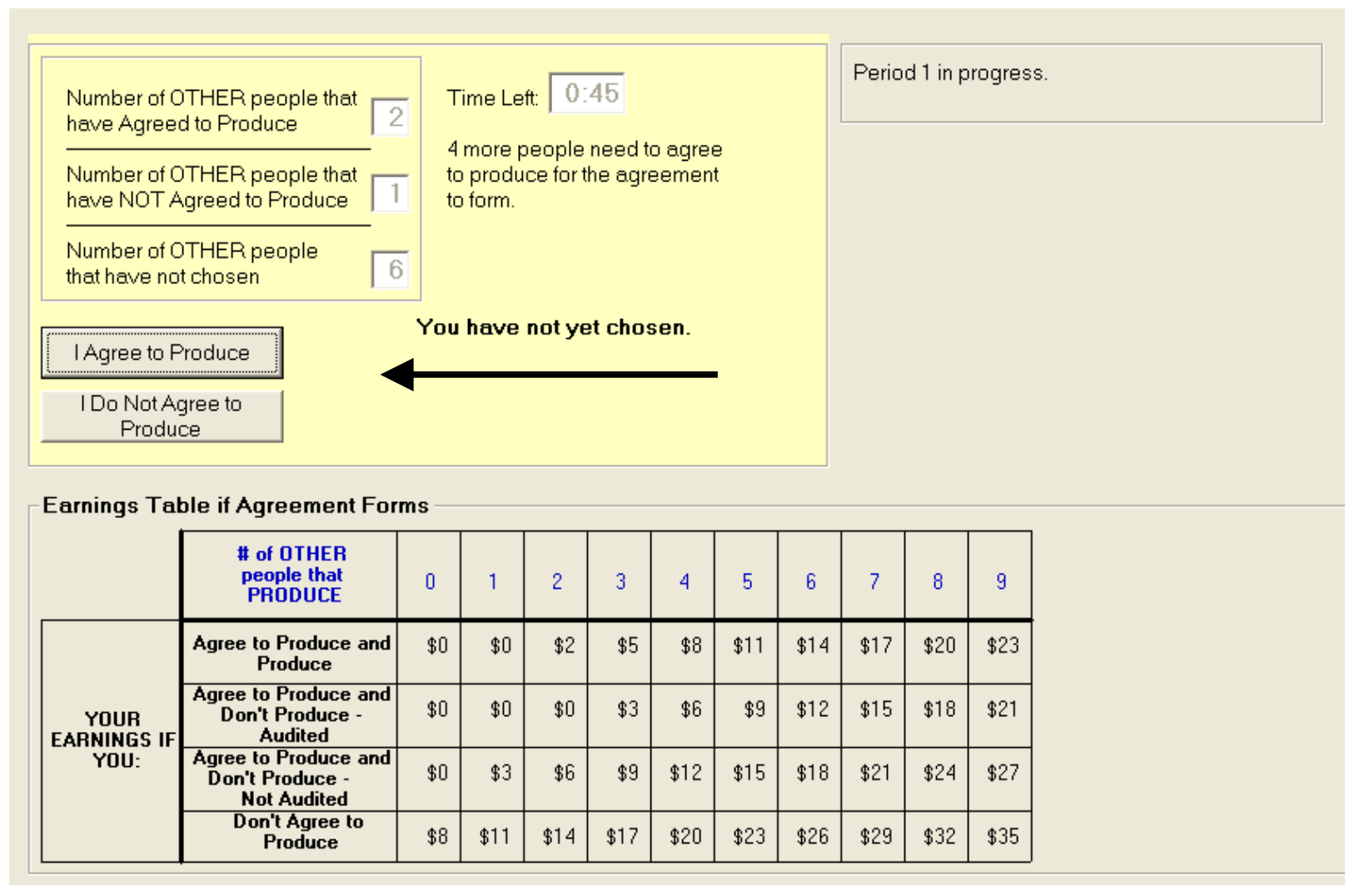

Notice also that you only have a limited amount of time to make your decision. The clock in the top area of the screen will indicate the time remaining. Also in the upper left area are boxes indicating the number of other members of the group who have agreed to produce, the number who did not agree to produce and the number of people who have not yet chosen. When you or another member in your group makes a decision, the corresponding box in the upper left area will quickly flash yellow.

In the example screen shot above, 2 other people have agreed to produce, 1 other person has not agreed to produce and 6 other people have not yet chosen. [Please now look up at the PowerPoint Display]

If at anytime the agreement forms (므 or more people agreed to produce), the screen will display that the agreement has formed. 
Once each member of the group has made their decision OR the time on the clock has run out, Stage 1 will be over. Those who did not make a decision by the time the clock runs out will be automatically counted as NOT agreeing to produce. At that point, a message box will pop-up indicating whether or not the agreement has formed.

\section{STAGE 2}

Recall, if the agreement forms (므 or more people agreed to produce), those who agreed to produce will have the opportunity to produce or not produce in Stage 2. The screen shot below is an example of Stage 2 in which you and 8 other group members agreed to produce. Notice that the produce/not produce buttons are in the center-right area of the screen.

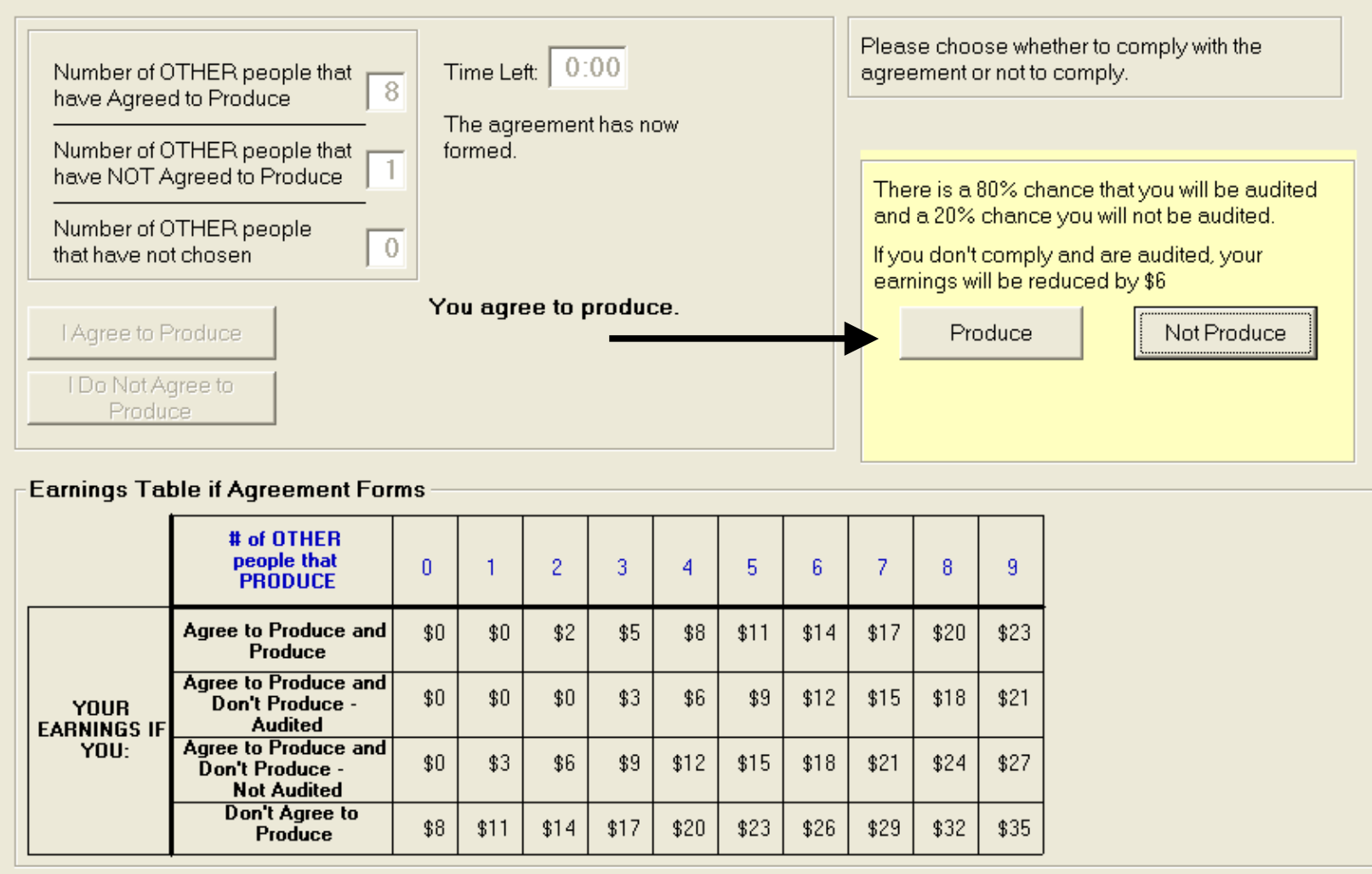

\section{END OF PERIOD}

After all groups have finished making their decisions in Stage 2, the period will be over. At that point a Period Results box will appear at the bottom of your monitor displaying the outcomes and your earnings for the period, your cumulative earnings thus far, information regarding the decisions made by you and all the members in your group and whether you were audited. An example of the Period Results Box is shown below. 


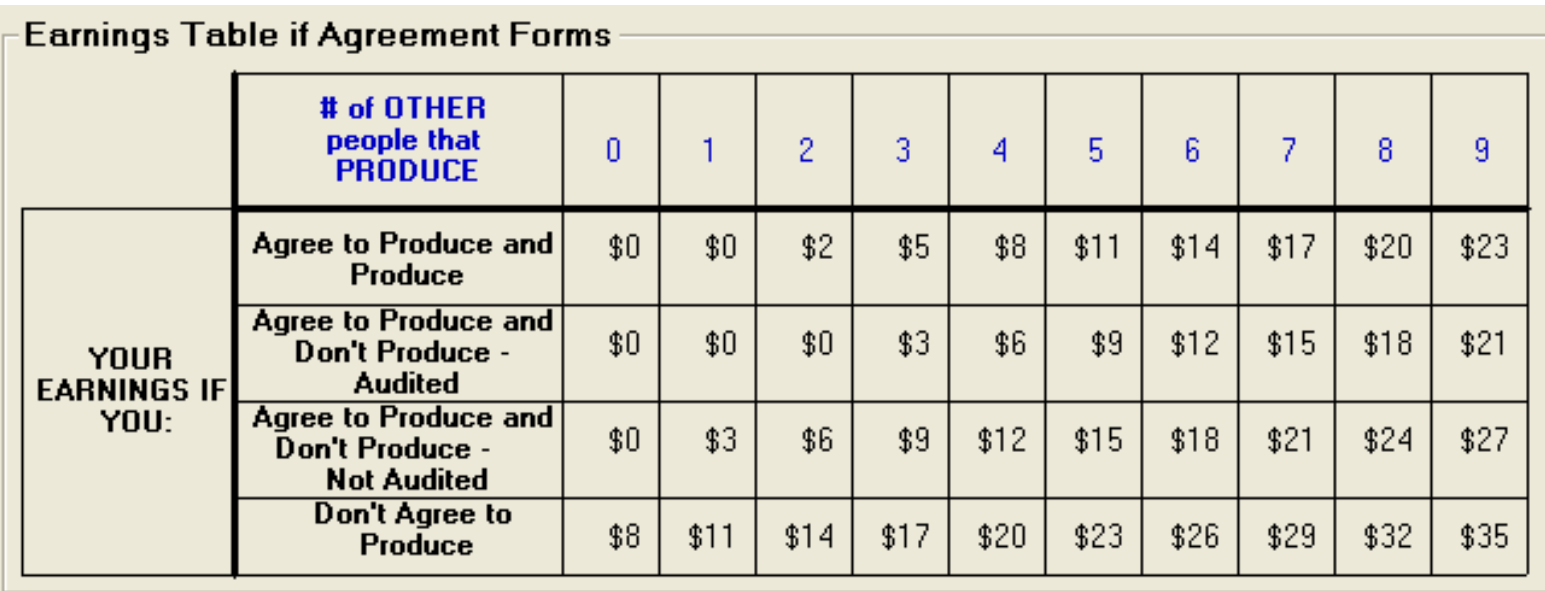

\section{Period Results}

STAGE 1 RESULTS:

8 OTHER people agreed to produce.

You agreed to produce.

STAGE 2 RESULTS:

7 OTHER people produced.

You produced.

You WERE audited

Your earnings HAVE NOT been reduced.
EARNINGS

Your production earnings for this period were $\$ 17$.

You were penalized $\$ 0$.

You earned $\$ 17.00$ in period 1 .

Your current total earnings are $\$ 17.00$.

In the example Period Results Table above, a total of 9 people agreed to produce in Stage 1. However in Stage 2, only 8 of those 9 people actually produced. The person in the example above chose to produce in Stage 2. The person was audited but not penalized because he/she chose to produce. A summary of the period and total earnings is also provided in the right-hand side of the box. [Please now look up at the PowerPoint Display]

Once you have had a chance to look at the Period Results you can click the green "Ready to Start" button at the top of the screen to begin the next period. Once all groups are ready, the next period will begin immediately.

\section{END OF EXPERIMENT}

The experiment will have 13 periods. You will be notified on your computer monitor once the experiment has ended and a summary screen with your total earnings will be displayed. At that point please stay seated and quiet and wait for your earnings to be paid to you. 


\section{SUMMARY}

- In Stage 1 during each period of play you choose either to agree to produce OR not agree to produce.

- If the agreement forms, those who agreed to produce in Stage 1 have the opportunity to produce or not produce in Stage 2. If the agreement does not form, ALL members of the group do not produce and the period ends. Each person earns 8 Experimental Dollars.

- The decisions made in Stage 2 will be audited with a probability of .8. Those people who are audited and who chose not produce will be fined 6 Experimental Dollars.

- If the agreement forms, the exact amount of money you earn each period is determined both by your choice and the choices made by the other members in your group. The Earnings Table if the Agreement Forms on your screen displays all of your earning possibilities.

- 10 Experimental Dollars = 1 U.S. Dollar. Fractions of a dollar will be rounded up to the nearest quarter.

- This experiment has 13 periods. You will not be matched up with the same 9 people for more than 1 period.

- Once the experiment has finished, please remain seated until you have received your earnings. THANKS!

Once the green "Ready to Start" button becomes active, you can click this button to begin the experiment. 


\section{Experiment instructions - costly enforcement-full}

\section{Experiment Instructions}

Thank you for agreeing to participate in this experiment. The instructions are fairly simple, and if you follow them carefully you may earn a considerable amount of money which will be paid to you in CASH at the end of the experiment. The exact amount of money you will earn will depend on your decisions, and the decisions made by the other participants, during this experiment.

\section{GENERAL DETAILS}

Please follow along while I read these instructions out loud. At times I will ask you to look up at the PowerPoint slides displayed on the monitors around the room. After I have completed reading through these instructions, a multiple period experiment will begin. The experiment will be run on the computer monitor at your station and you will use the mouse to make all of your decisions. Please do not talk to each other or move around during this experiment! Please make sure all cell phones and other personal electronic equipment are switched off.

Throughout this session, your earnings will be reported in experimental dollars. 10 Experimental Dollars equals 1 US dollar. Your earnings, in US dollars, will be paid to you at the end of the experiment in cash.

\section{YOUR DECISIONS}

During each period of this experiment you have the opportunity to earn money by deciding whether or not to produce one unit of an unspecified product. There will be 13 periods.

You will be in a group with 9 OTHER members each of whom will be presented with the same choices. The group assignments will change after every period. You will not be matched up with the same other 9 people for more than a single period.

The exact amount of money you will earn will depend on YOUR decisions as well as the decisions of the OTHER members in your group. Likewise, YOUR decisions will affect the earnings of the OTHER members in your group.

\section{STAGE 1}

Before any production decisions are actually made, in Stage 1 of each period you first must decide whether or not you are willing to join an agreement with the other members in your group. You and the other 9 members of your group will choose either to agree to produce or not agree to produce one unit of the product. 


\section{WHAT AGREE TO PRODUCE AND NOT AGREE TO PRODUCE MEAN}

Choosing agree to produce means you are willing to join an agreement with the other members in your group. The agreement will only form if all $\mathbf{1 0}$ group members choose agree to produce, otherwise the agreement will not form.

- If the agreement forms:

You and the other 9 group members all move onto Stage 2 where each of you will have the opportunity to 'comply' with what you agreed to. That is, in Stage 2 you are given the opportunity to either produce or not produce.

- If the agreement does not form:

Each person in the group does not produce the product, the period ends and each person earns 8 Experimental Dollars.

To recap, once each person in your group has made his/her decision to agree or not agree to produce, one of two things can happen:

(1) If all 10 members of the group chose agree to produce in Stage 1, then everyone moves to Stage 2. In Stage 2, you and the other 9 group members are given the opportunity to produce or not produce.

(2) If less than 10 members in the group chose agree to produce in Stage 1, then the period ends and ALL members of the group automatically do not produce the product and each person earns 8 experimental dollars.

[ARE THERE ANY QUESTIONS SO FAR?] 


\section{STAGE 2}

To reiterate, if all 10 group members agree to produce in Stage 1, everyone then gets to decide either to produce or not produce in Stage 2.

The decisions made in Stage 2 will be audited with a probability of .8. Meaning, there is an $80 \%$ chance each person in the group is audited and a $20 \%$ chance each person in the group is not audited. Those people who are audited and who chose not produce will be fined $\mathbf{6}$ experimental dollars. People who are audited and chose produce, or are not audited, will not be fined.

[Flip to next page] 


\section{YOUR EARNINGS}

Recall, if the agreement does not form, everyone in the group does not produce the product and each member earns 8 experimental dollars. At that point the period ends.

The Earnings Table if the Agreement Forms, provided below, shows your earnings for each possible outcome when the agreement forms. This is the exact table you will be given on your computer monitor.

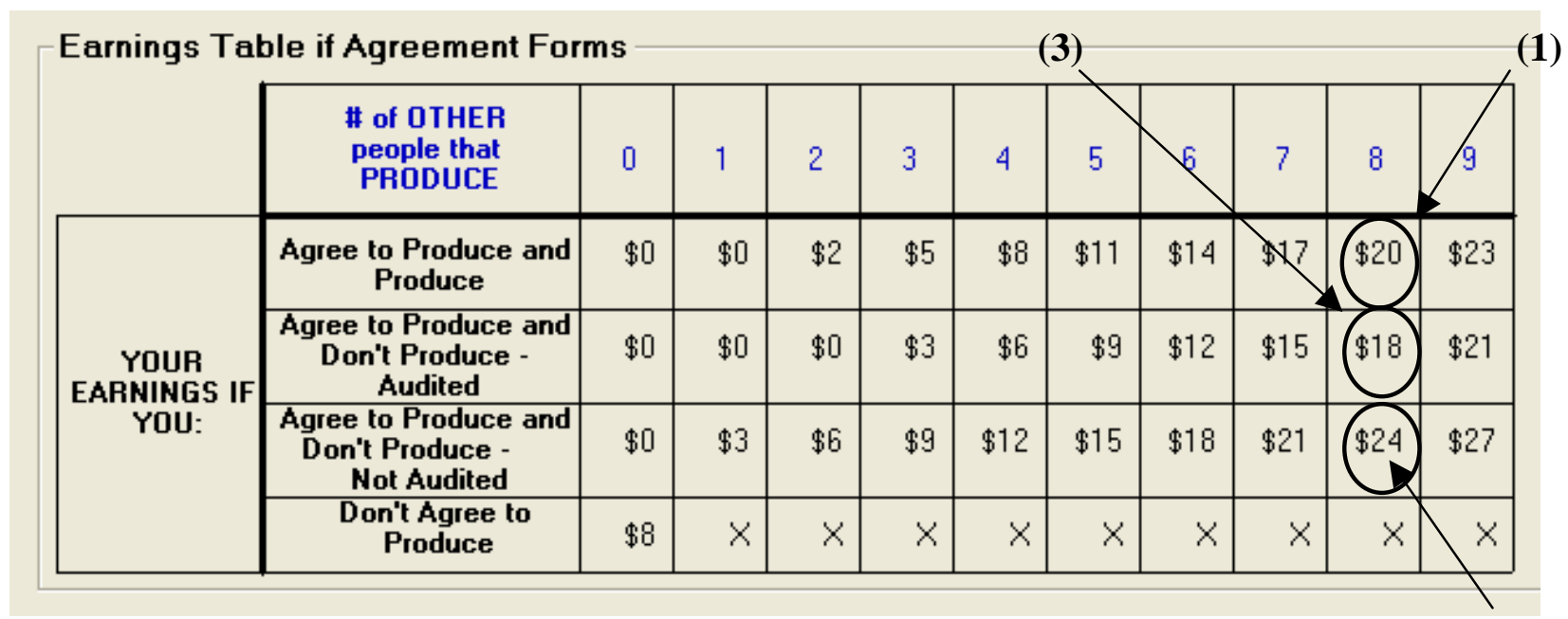

The bottom four rows of the table list your four possible choices and potential earnings. Notice that your information is all in black. The top row of the table lists the number of other members in your group choosing to produce ( 0 to 9 people). Notice that the information pertaining to the other members in your group is in blue. [Please look up at the PowerPoint Display]

To get a feel for how the table works, let’s go through a few examples:

Example: In Stage 2, suppose that 8 other people in your group chose to produce and 1 other person chose to not produce. Given this, your period earnings would be one of the following:

(1) If you chose to produce in Stage 2, you would earn 20 Experimental Dollars.

(2) If you chose not produce in Stage 2 and WERE NOT audited, you would earn 24 Experimental Dollars.

(3) If you chose not produce in Stage 2 and WERE audited, you would be charged a penalty of 6 and therefore you would earn 18 Experimental Dollars.

Note that each of these scenarios is numbered on the table above. 
Practice Questions: Please follow along as I read the following practice questions. For each question, fill in the blank with the correct answer. After you have had a chance to answer the questions, I will then go over the answers.

Question 1: Suppose you have not yet made your decision whether or not to agree to produce in Stage 1. Also assume that the other 9 members of your group have all made their decisions. Specifically, the 9 other people have all agreed to produce.

- Given the choices made by your group members, if you chose to agree to produce would the agreement form $(\mathrm{Y} / \mathrm{N})$ ?

- Given the choices made by your group members, if you chose to NOT agree to produce would the agreement form $(\mathrm{Y} / \mathrm{N})$ ? How many Experimental Dollars would you earn in this case?

[Please now look up at the PowerPoint Display]

Question 2: Suppose you and the other 9 members of your group agreed to produce in Stage 1. Once in Stage 2, what would your experimental earnings be if:

- 7 other group members chose to produce, 2 chose not to produce and you chose to produce?

- 7 other group members chose to produce, 2 chose not to produce and you chose not to produce and were NOT audited?

- 7 other group members chose to produce, 2 chose not to produce and you chose not to produce and were audited?

[Please now look up at the PowerPoint Display] 


\section{HOW THE EXPERIMENT WORKS}

Once we have finished reading the instructions you will begin the experiment. To do so, you must click the green "READY TO START” button in the top right corner of your screen.

Once each member of your group has clicked the button, the first period will begin.

\section{STAGE 1}

The image below is an example of the first screen that will appear during each period of play. Notice that the I agree to produce and I do not agree to produce buttons are in the center-left area of the screen. Once any person in the group makes a decision, the buttons become inactive for 1 second in order to notify the entire group that a decision has been made.

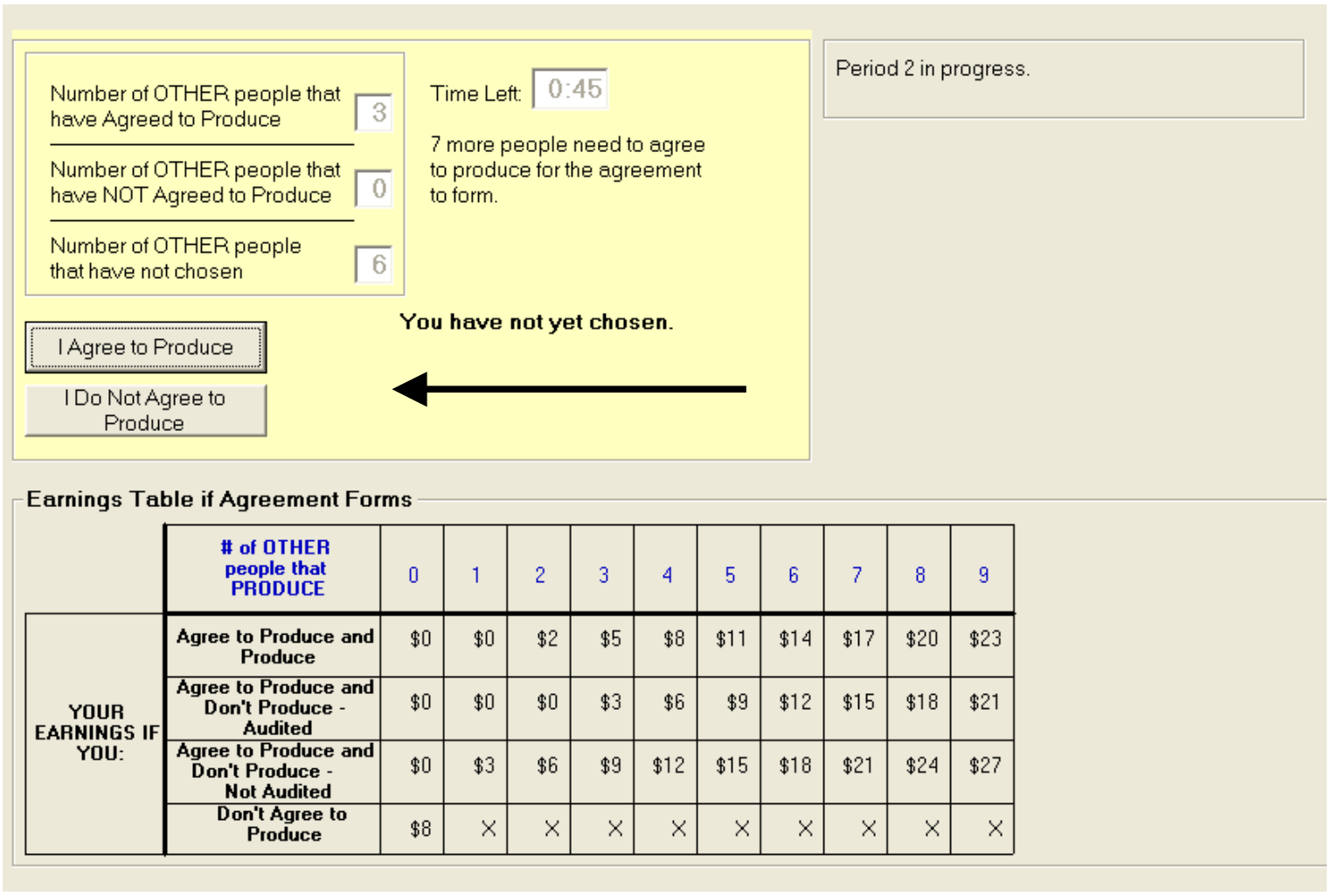

Notice also that you only have a limited amount of time to make your decision. The clock in the top area of the screen will indicate the time remaining. Also in the upper left area are boxes indicating the number of other members of the group who have agreed to produce, the number who did not agree to produce and the number of people who have not yet chosen. When you or another member in your group makes a decision, the corresponding box in the upper left area will quickly flash yellow. 
In the example screen shot above, 3 other people have agreed to produce, 0 other people have not agreed to produce and 6 other people have not yet chosen. [Please now look up at the PowerPoint Display]

Once each member of the group has made their decision OR the time on the clock has run out, Stage 1 will be over. Those who did not make a decision by the time the clock runs out will be automatically counted as NOT agreeing to produce. At that point, a message box will pop-up indicating whether or not the agreement has formed.

\section{STAGE 2}

Recall, if you and the other 9 group members all agree to produce, you will have the opportunity to produce or not produce in Stage 2. The screen shot below is an example of Stage 2. Notice that the produce/not produce buttons are in the center-right area of the screen.

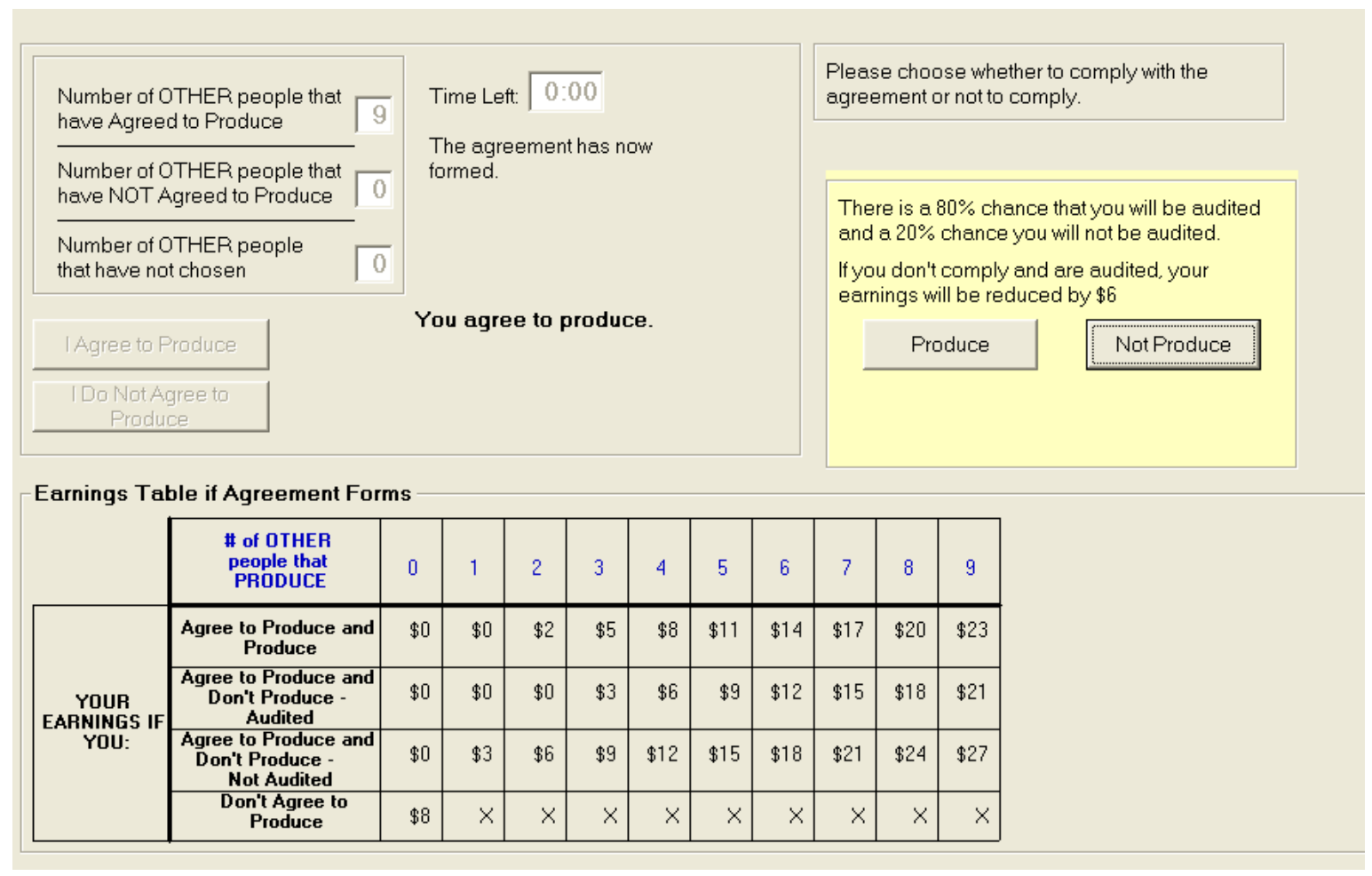

\section{END OF PERIOD}

After all groups have finished making their decisions in Stage 2, the period will be over. At that point a Period Results box will appear at the bottom of your monitor displaying the outcomes and your earnings for the period, your cumulative earnings thus far, information regarding the decisions made by you and all the members in your group and whether you were audited. An example of the Period Results box is shown below. 


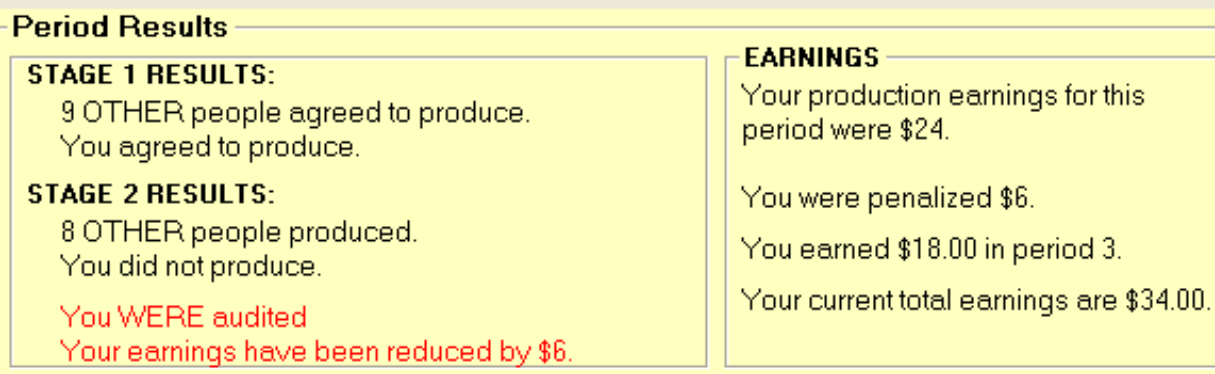

In the example Period Results box above, all group members agreed to produce in Stage 1. However in Stage 2, only 8 of the 10 people actually produced. The person in the example above chose not to produce in Stage 2. The person was audited and therefore penalized 6 experimental dollars because he/she chose not to produce. A summary of the period and total earnings is also provided in the right-hand side of the box. [Please now look up at the PowerPoint Display]

Once you have had a chance to look at the Period Results you can click the green "Ready to Start" button at the top of the screen to begin the next period. Once all groups are ready, the next period will begin immediately.

\section{END OF EXPERIMENT}

The experiment will have 13 periods. You will be notified on your computer monitor once the experiment has ended and a summary screen with your total earnings will be displayed. At that point please stay seated and quiet and wait for your earnings to be paid to you. 


\section{SUMMARY}

- In Stage 1 during each period of play you choose either to agree to produce OR not agree to produce.

- If the agreement forms (everyone agrees to produce) in Stage 1, everyone will have the opportunity to produce or not produce in Stage 2. If the agreement does not form, ALL members of the group do not produce and the period ends. Each person earns 8 Experimental Dollars.

- The decisions made in Stage 2 will be audited with a probability of .8. Those people who are audited and who chose not produce will be fined 6 Experimental Dollars.

- If the agreement forms, the exact amount of money you earn each period is determined both by your choice and the choices made by the other members in your group. The Earnings Table if the Agreement Forms on your screen displays all of your earning possibilities.

- 10 Experimental Dollars = 1 U.S. Dollar. Fractions of a dollar will be rounded up to the nearest quarter.

- This experiment has 13 periods. You will not be matched up with the same 9 people for more than 1 period.

- Once the experiment has finished, please remain seated until you have received your earnings. THANKS!

Once the green "Ready to Start" button becomes active, you can click this button to begin the experiment. 